Linköping Studies in Science and Technology

Dissertation No. 1662

\title{
MOCVD growth of GaN-based high electron mobility transistor structures
}

\author{
Jr-Tai Chen
}

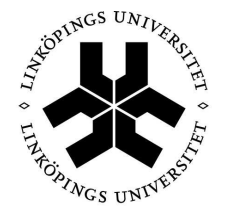

Linköping University

Semiconductor Materials Division

Department of Physics, Chemistry, and Biology

Linköping University

SE-581 83 Linköping, Sweden 
Cover: surface morphology of a GaN high electron mobility transistor structure grown on a native GaN substrate. The image was obtained with an atomic force microscope.

\section{(C) Jr-Tai Chen 2015}

ISBN: 978-91-7519-073-0

ISSN: 0345-7524

Printed by LiU-Tryck, Linköping, Sweden 2015 
謹以此書, 獻給我慈愛的父親。

In loving memory of my dear father. 


\section{Abstract}

Wide bandgap group-III nitride semiconductors like GaN, AlN, and their alloys are very suitable for the use in high-power, high-frequency electronics, as a result of their superior intrinsic properties. The polarization-induced high-density and high-mobility two-dimensional electron gas (2DEG) forming in (0001) oriented $\mathrm{AlGaN} / \mathrm{GaN}$ heterostructures enable the epitaxial structure to be utilized for high electron mobility transistors (HEMTs). Outstanding power handling and record high frequency have been demonstrated from GaN-based HEMT devices over time. However, the shortterm stability and the long-term reliability of the device performances remain problematic. In order to make GaN HEMT technology truly take off and breach the civilian market like automotive, telecommunication applications, the problems need to be solved to justify its relatively high cost over the solutions based on Si and GaAs technologies.

At the material level, there are two major challenges; one is the reduction of highdensity structural defects in heteroepitaxially grown layers when foreign substrates are used, and the other is the control of "deep" electron traps forming in the middle of the "wide" bandgap by intrinsic defects or extrinsic impurities.

The main idea of the present work was therefore to tackle these material issues directly, using an approach called bottom-to-top optimization to improve the overall quality of GaN-based HEMT epitaxial structures grown on semi-insulating (SI) SiC and native $\mathrm{GaN}$ substrates. The bottom-to-top optimization means an entire growth process optimization, from in-situ substrate pretreatment to the epitaxial growth and then the cooling process. Great effort was put to gain the understanding of the influence of growth parameters on material properties and consequently to establish an advanced and reproducible growth process. Many state-of-the-art material properties of GaNbased HEMT structures were achieved in this work, including superior structural integrity of AlN nucleation layers for ultra-low thermal boundary resistance, excellent control of residual impurities, outstanding and nearly-perfect crystalline quality of $\mathrm{GaN}$ epilayers grown on $\mathrm{SiC}$ and native $\mathrm{GaN}$ substrates, respectively, and record-high room temperature 2DEG mobility obtained in simple $\mathrm{AlGaN} / \mathrm{GaN}$ heterostructures.

The epitaxial growth of the wide bandgap III-nitride epilayers like GaN, AlN, AlGaN, and InAlN, as well as various GaN-based HEMT structures was all carried out in a hot-wall metalorganic chemical vapor deposition (MOCVD) system. A variety of structural and electrical characterizations were routinely used to provide fast feedback 
for adjusting growth parameters and developing improved growth processes, such as optical microscopy (OM), atomic force microscopy (AFM), x-ray diffraction (XRD), capacitance-voltage measurement (CV) as well as sheet resistance, 2DEG density and mobility measurements based on contactless microwave-based techniques. The advanced characterizations like secondary ion mass spectrometry (SIMS) and transmission electron microscopy (TEM) were employed on selective samples.

The results of the present work are summarized accordingly with the papers, as listed below.

In Paper 1, we showed that the crystalline quality of thin AlN nucleation layers and $\mathrm{GaN}$ buffer layers in HEMT structures grown on $\mathrm{SiC}$ substrates can be considerably improved by optimizing the in-situ $\mathrm{SiC}$ surface pretreatment temperature. It was highlighted that oxygen- and carbon-related contaminants were still present on the $\mathrm{SiC}$ surface treated at $1200{ }^{\circ} \mathrm{C}$ in $\mathrm{H}_{2}$-contained MOCVD ambient, which would adversely affect the subsequent epitaxial growth. The correlations between the thermal resistance and the structural parameters in the $\mathrm{GaN} / \mathrm{SiC}$ interfacial region are present. Record low thermal boundary resistance of the GaN-on-SiC epitaxial platform for HEMT structures was achieved by reducing the thickness of the AlN nucleation layer.

In Paper 2, we demonstrated that high tuneability of residual carbon doping for GaN can be realized in our hot- wall MOCVD reactor by means of controlling growth temperature and V/III ratio. We also investigated the impact of the residual carbon on 2DEG properties and found that the carbon concentration in the vicinity of the 2DEG must be reduced to minimize carbon-related trapping effects that could significantly decrease 2DEG density and mobility.

In Paper 3, we demonstrated that room-temperature 2DEG mobility can be greatly improved in $\mathrm{AlGaN} / \mathrm{GaN}$ heterostructures from $\sim 1650$ to $\sim 2250 \mathrm{~cm}^{2} / \mathrm{V}$-s, without the assistance of an AlN exclusion layer, which is traditionally inserted into the heterostructures to enhance the mobility. Abruptly changing the $\mathrm{Al}$ transition from the $\mathrm{GaN}$ to the $\mathrm{AlGaN}$ in the heterointerface was evidenced as the key to enhance the carrier confinement, consequently improving the mobility. The interface sharpening process was also presented.

In Paper 4, we integrated all advanced growth processes developed during my Ph.D study into one recipe for growth of high-quality and outstanding-uniformity AlGaN/GaN HEMT structures on $100 \mathrm{~mm} \mathrm{SiC}$ substrates. Very low spread of the sheet resistance $(1.1 \%)$ and the total thickness $(2.1 \%)$ over the large epiwafer was achieved. In addition, the AlN nucleation growth was further refined with an enhanced 2D growth technique to make the nucleation layer completely coalesced at a very early growth stage and also to obtain excellent crystalline quality with high reproducibility. 
These results embody the success of the bottom-to-top optimization approach for MOCVD growth of GaN-on-SiC high-mobility transistor structures.

In Paper 5, homoepitaxial growth of $\mathrm{GaN}$ in our MOCVD process was developed. Severe surface decomposition of SI GaN templates was observed in high-temperature $\mathrm{H}_{2}$-contained MOCVD ambient prior to epitaxial growth. A modified temperature ramping process was proposed and its effectiveness to preserve the surface of GaN template and substrates under the harsh MOCVD environment was shown. With the proposed heating process, we demonstrated state-of-the-art structural properties of a GaN-based HEMT epitaxial structure realized on a $10 \times 10 \mathrm{~mm}^{2}$ SI native GaN substrate, with full width at half maximum of the x-ray rocking curves of 14 and 21 arcsec for the GaN (002) and (102) peaks, respectively, and a highly uniform bilayer step morphology. The impurity profile from the homoepitaxial interface to the proximity of $2 \mathrm{DEG}$ channel was also optimized to prevent a parallel conduction path in the interface and trapping effects in the channel.

In Paper 6, the influence of the residual carbon doping levels and profileson the performances of HEMT devices was investigated. The current collapse was dramatically improved from $78.8 \%$ to $16.1 \%$, when the uniform doping profile with high carbon concentration in the GaN buffer layer is replaced with the stepped doping profile. Besides, the stepped profile delivered good buffer insulation with the same magnitude of the leakage current as the uniform profile. However, the uniform doping profile with low carbon concentration exhibited poor buffer insulation despite that its current collapse was low. Moreover, we found two trap levels at $0.15 \mathrm{eV}$ and $0.59 \mathrm{eV}$ in the high-doped material, but only one level at $0.59 \mathrm{eV}$ in the low-doped material.

In Paper 7, the impact of interface sharpness of an $\mathrm{AlGaN} / \mathrm{GaN}$ heterostructure on the performances of HEMT devices was investigated. The gated Hall measurements revealed that the sharp-interface heterostructure maintained a higher mobility compared to the heterostructures with an $\mathrm{AlN}_{\mathrm{ex}}$ layer or a non-optimized interface, when the 2DEG was drawn closer to the AlGaN in the interface. The overall HEMT performances of the sharp-interface heterostructure were shown to outperform the other heteroctructures. 


\section{Populärvetenskaplig sammanfattning}

Nitridbaserade halvledarmaterial såsom GaN, AlN och dess legeringar är mycket väl lämpade för högeffekt och högfrekvenstillämpningar. Då dessa material kombineras kan t.ex. "High Electron Mobility Transistor" (HEMT) komponenter designas. En HEMT komponent karaktäriseras av en polariseringsinducerad tvådimensionell elektrongas (2DEG) som bildas i gränsskiktet $\mathrm{AlGaN} / \mathrm{GaN}$ och de elektroner som utgör den tvådimensionella gasen kännetecknas av en hög mobilitet. Ett av problemen med nitridbaserade HEMT strukturer är dess långtidsstabilitet. Detta problem måste lösas om GaN HEMT tekniker ska bli en kommersiell framgång.

Sett ur ett materialperspektiv består utmaningarna framförallt av att minska densiteten av de strukturella defekterna samt att styre bildandet av djupa defektnivåer, som fungerar som elektronfällor. Dessa djupa defektnivåer är lokaliserade i mitten av bandgapet och är relaterade till intrinsiska defekter och/eller oavsiktligt inkorporerade dopatomer.

Idén med detta arbete var lösa dessa utmaningar genom att använda sig av en "bottomto-top" optimering, d.v.s. att optimera processen för tillverkning av HEMT strukturen från det att substratet börjar värmas, odling av själva strukturen och till dess att nedkylningsprocessen är avklarad. Mycket arbete har lagts på att förstå hur själva tillväxtprocessen fungerar och hur den påverkar den slutliga komponenten. I detta arbete inkluderas bland annat utveckling av ett AlN nukleationsskikt med extremt låg termisk resistans, en utmärkt kontroll av inkorporationen av dopämnen, en hög strukturell kvalité och en rekordhög 2DEG mobilitet för $\mathrm{AlGaN} / \mathrm{GaN}$ heterostrukturer.

Tillväxt av halvledarmaterialen GaN, AlN, AlGaN och InAlN har utförts i en hetväggs MOCVD reaktor och har karaktäriserats både elektriskt, strukturellt och optiskt med flera olika tekniker, såsom optiskt mikroskop (OM), atmokraftmikroskop (AFM), röntgendiffraktion (XRD), kapacitans-volt mätningar (CV) och kontaktlös mikrovågsbaserad teknik för att bestämma skiktresistans och mobilitet för elektrongasen. Kompletterande mätningar har gjorts med sekundärjonmasspektrometri (SIMS) och transmissionselektronmikroskopi (TEM)

I denna avhandling har resultaten ifrån arbetet sammanställts i följande artiklar.

Papper 1.

Här visar vi att den kristallina kvalitén av tunna AlN nukleationskikt och GaN buffert lager i HEMT strukturer odlade på SiC substrat, avsevärt kan förbättras genom att 
optimera temperaturen för behandlingen av $\mathrm{SiC}$ ytskiktet då substratet värms upp. Vi visar att syre- och kolatomer fortfarande kontaminerar $\mathrm{SiC}$ ytan vid så hög temperatur som $1200{ }^{\circ} \mathrm{C}$ i vätgasmiljö, vilket i sin tur påverkar efterföljande tillväxt. Relationen mellan den termiska resistansen och den strukturella kvalitén i $\mathrm{GaN} / \mathrm{SiC}$ regionen presenteras. En rekordlåg termisk resistans erhölls för en HEMT struktur odlad på ett $\mathrm{SiC}$ substrat genom att reducera AlN nukleationsskiktets tjocklek.

\section{Papper 2.}

Här presenterar vi möjligheten att ändra kolhalten i GaN buffert skiktet genom att ändra tillväxttemperaturen och V/III förhållandet. Vi har också undersökt kolhalten i närheten av den 2DEG och observerat att en minskning av kolkoncentrationen leder till en reducering av kolrelaterade elektron fällor, som i sin tur minskar både elektronkoncentrationen och elektronmobiliteten av elektrongasen.

\section{Papper 3.}

Här visar vi att 2DEG mobiliteten för $\mathrm{AlGaN} / \mathrm{GaN}$ heterostrukturer vid rumstemperatur kan förbättras avsevärt från 1650 till $2150 \mathrm{~cm}^{2} / \mathrm{Vs}$ utan att addera ett AlN exklusionslager, vilket är en vedertagen design för att förbättra mobiliteten i HEMT strukturer. Genom att skapa en abrupt aluminiumkoncentrationsövergång för AlGaN skiktet kunde elektroninneslutningen förbättras och därigenom förbättrades även elektronmobiliteten. Tillväxtprocessen av abrupta gränsytor i HEMT strukturer presenterades också.

\section{Papper 4.}

I detta papper integrerar vi de resultat vi har presenterat i papper 1-3. Vi visar på tillväxt av AlGaN/GaN HEMT struktur på $100 \mathrm{~mm} \mathrm{SiC} \mathrm{med} \mathrm{mycket} \mathrm{hög} \mathrm{Rsh}$ uniformitet $(1.1 \%)$ och med en total tjockleksvariation på $2.1 \%$. AlN nukleationsskiktet har också förbättrats ytterligare med hjälp av en 2D tilllväxtteknik som skapar en helt täckt AlN yta väldigt tidigt i tillväxtprocessen. Detta skikt har en mycket hög kristallin kvalité och kan framställas på ett reproducerbart sätt. Dessa resultat möjliggjorde en "bottom-to-top" optimering av en HEMT struktur odlad på ett $\mathrm{SiC}$ substrat.

\section{Papper 5.}

I detta papper har vi utvecklat homoepitaxi av GaN på GaN substrat. Kraftig degradering av den SI GaN yta n observerades då provet värmdes upp till hög temperatur i en vätgasmiljö färe tillväxt. En modifierad upprampning av temperaturen har tagits fram och dess effekt av att bevara $\mathrm{GaN}$ substratets yta har presenterats. Med den föreslagna upprampningsprocessen demonstrerar vi "state-of-the-art" strukturella egenskaper på en GaN baserad HEMT struktur odlad på ett $10 \times 10$ mm stort SI GaN 
substrat. Mängden föroreningar i närheten av 2DEG kanalen optimerades också, detta för att undvika en parallell elektrisk ledande kanal vid interfacet samt att minimera möjliga elektriska fällor i kanalen.

\section{Papper 6.}

I detta papper undersöker vi hur bakgrundsdopningen av kol påverkar en HEMT struktur. Strömkollapsen förbättrades från $78.8 \%$ till $16.1 \%$ när koldopningsprofilen ändrades från att vara en homogent dopad profil till att bestå av en trappstegsprofil. Trappstegsprofilen har också samma goda isolation i buffert skiktet som en homogent dopad buffert. Dock, den homogent dopade bufferten med låg kolkoncentration resulterade i en låg isolation även om strömkollapsen var låg. Vi upptäckte också fällor vid energinivåerna $0.15 \mathrm{eV}$ och $0.59 \mathrm{eV}$ i det högdopade materialet men endast en fälla. $0.59 \mathrm{eV}$, i det lågdopade materialet.

\section{Papper 7.}

I detta papper undersöker vi hur prestandan i en $\mathrm{AlGaN} / \mathrm{GaN}$ heterostruktur påverkas av abruptheten i gränsskiktet. Gate styrd hall mätningar visar att en skarp övergång i gränsskiktet resulterar $\mathrm{i}$ en högre mobiltet jämfört med då man använder sig av ett $\mathrm{AlN}_{\mathrm{ex}}$ lager eller ett icke optimerat gränsskikt då 2DEGen drog sig närmare $\mathrm{AlGaN}$ skiktet $\mathrm{i}$ en $\mathrm{AlGaN} / \mathrm{GaN}$ övergång. Den optimerade HEMT processen med det optimerade gränsskiktet visade sig vara överlägset de andra heterostrukturerna. 


\section{Preface}

The work presented in this doctorate thesis is a result of my Ph.D. study for growth and characterization of GaN-based high electron mobility epitaxial structures on $\mathrm{SiC}$ and GaN substrates. The research was conducted between February 2009 to April 2015 in the division of Semiconductor Materials in the department of Physics, Chemistry, and Biology (IFM) in Linköping University (LiU). The financial support was provided by the Swedish Research Council (VR), the Swedish Foundation for Strategic Research (SSF), the European project of High Quality European GaN Wafer on SiC Substrates for Space Applications (EuSiC), and the European and the Swedish projects of Manufacturable GaN (Manga).

This thesis contains an introduction to the research field of growth and characterization of GaN-based high electron mobility epitaxial structures. The scientific outcomes and understanding from the study are presented in the seven included papers.

Jr-Tai Chen

Linköping, April 2015 


\section{Acknowledgement}

My $\mathrm{PhD}$ career has been very blessed. I would like to take this opportunity to acknowledge those people who have contributed to my research and/or my life over the past several years. My gratitude goes to .....

Erik Janzén, for all the support and trust that he has given me over the past six years. It is because of his encouragement, strong financial support, and patience; I could gain a rich experience in material growth. And there were countless number of meetings with him in his office, discussing results, solving problems, and refining new ideas together. I really enjoyed the time.

Urban Forsberg, for having being so supportive to me, and keeping me stay positive and down-to-earth, especially when no any breakthrough was made in the first few years of my $\mathrm{PhD}$ carrier. It is always joyful to talk with him discussing our reactor, growth process and the meaning of a life. And our rebellious Solaris would not be tamed if without him.

Magnus Weideryd and Björn Jonsson, for great supports from Swedish Defense Material Administration, FMV, to our HEMT projects for many years.

Dr. Kuei-Hsien Chen and Dr. Li-Chyong Chen, for supporting me all the way to come studying in Sweden. My life course was thus changed and I am very happy with the outcome.

Ching-Lien Hsaio, for his forthright comments and suggestions from time to time. I always find them inspiring and motivating. He was the one in Taiwan training me to have a right attitude and a persistent mind for material growth.

Anders Lundskog, for EVERYTHING. He somehow sparked my interest to come to Linköping for this $\mathrm{PhD}$ study when we met and hung out in Taiwan. I also learned much from him, from daily English speaking, Swedish culture and demeanors, to material growth and characterizations. I really appreciate it.

Chih-Wei Hsu, for his back-ups and encouragement. There were many tough times we walked through together. Additional big thanks to him for all the support, assistance and discussion in lab and in office, especially in the very periods for material deliveries and paper writing.

Anelia Kakanakova-Georgieva, for many fruitful and inspiring discussions with her. I appreciate the time she spent for me. 
Daniel Nilsson, for reducing my workload in lab tremendously. Many Thanks! It has been truly a pleasure to work closely with him in the last several months. I particularly love discussing the experimental results with him over the ping pong table. Let's keep doing so!

Ian Booker, for always taking my questions seriously. He was one of the very few people I could find in IFM to discuss with and talk to in late evenings or nights!

Olle Kordina, for sharing plenty of his valuable experience with me during the business trips. It is fun to work with him.

Anne Henry, for taking care of me at the beginning of my $\mathrm{PhD}$ study with her ingenuous and warm heart.

Ivan Ivanov, Justinas Palisaitis, Leif Johansson, Vanya Darakchieva, Chriya Virojanadara, Chao Xia, Jawad ul Hassan, Plamen Paskov, Nyuyen Tien Son, Xuan Thang Trinh, Per Persson, and Imguar Persson, for constantly helping me to explore material properties and sharing their vast knowledge with me

Per Olof Holtz, Fredrik Karlsson, and Martin Eriksson, for always being kind and supportive.

Sven Andersson, Eva Wilbom, and Ildiko Farkas, for dealing with my urgent requests again and again.

Jiang-Qiang Zhu, for the helps in many different aspects. He was the first friend I made in IFM.

All the people in Semiconductor Materials Division, for the friendly and helping atmosphere.

Dr. Niklas Rorsman and Chalmers people, for processing our materials to devices and providing numerous important feedbacks so that we can keep improving the material quality accordingly.

Chih-Wei, Lorina, Alex and Fiona, and Dr. Hsaio, Su-Ni, and all of your beautiful kids, for the constant care and wonderful times we spent together. They are my family-like friends in Sweden. I have been treated with innumerable home-taste dinners from them, which comfort my nostalgia and help me through the periods when I devote myself to the work as if there is no tomorrow..

Stefano, Anders, Stina, Daniel, Martin, Markus, Andrea, Patrick and Abeni, for their precious friendship. With them, my life in Linköping was thus enriched with joyful events outsides the campus and interesting talks during lunches. 
Hill, Tina, Kate, and all of my close friends in Taiwan, for their concerns from different corners of the world.

My sister, brother-in-law, and the cuties Blair and Blake, for taking care of the family and my matters in Taiwan. The happiness and laughter they spread are my true sunshine.

Wanting, my love, for endless support and countless hours accompanying me on the other side of Skype. Our love conquered the long distance over a thousand of miles, and she makes my life complete.

My mother and my father, for their all-enduring and selfless love. Their love, care and support are the source of my strength and confidence. They are a big part of reason for my success. My gratitude to them is beyond words.

我慈愛的母親 : 謝謝您為我付出的一切。我成功背後的力量一直是來至您無私與 無盡的愛。只有與您分享我的榮耀和幸福, 我的人生才能充滿意義。

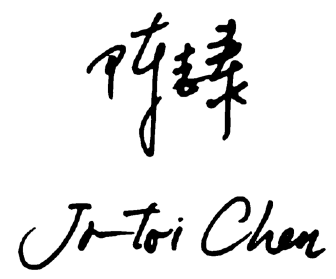

2015-04-07 


\section{Content}

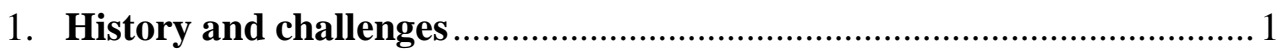

GaN-based microwave power devices ......................................................... 1

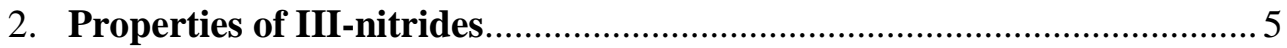

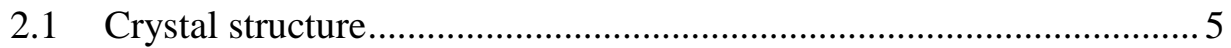

2.2 Bandgap property and engineering ................................................... 7

2.3 Built-in polarizations ................................................................. 9

3. Fundamentals of GaN-based HEMT structures .................................... 11

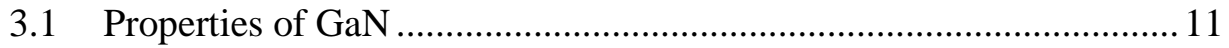

3.2 GaN-based high electron mobility transistor..................................... 12

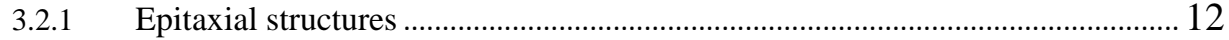

3.2.2 Origin of the two-dimensional electron gas ....................................................... 13

3.2.3 Transport properties of 2DEG............................................................................. 16

4. MOCVD growth of GaN-based HEMT structures.................................. 19

4.1 Fundamentals of the MOCVD process ............................................. 19

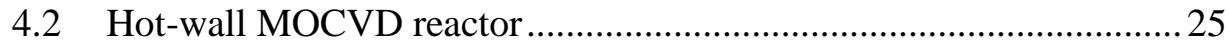

4.3 Epitaxial growth process of GaN-based HEMT structures .................2 27

4.3.1 Substrate choices............................................................................................. 27

4.3.2 Substrate pretreatment............................................................................. 28

4.3.3 Growth of the AlN nucleation layer ............................................................... 30

4.3.4 Growth of the GaN buffer layer...................................................................... 31

4.3.5 Growth of the HEMT active layers …………………………………………….... 33

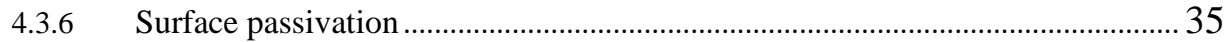

5. Characterizations of GaN-based HEMT structures.................................37

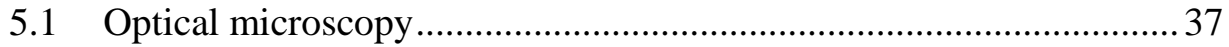

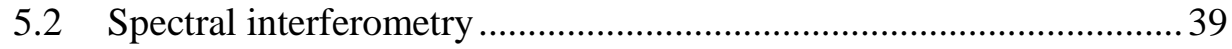

5.3 Contactless electrical measurements ................................................. 40 
5.4 Mercury-probe capacitance-voltage measurement............................. 42

5.5 Atomic force microscopy ................................................................ 44

5.6 High-resolution X-ray diffractometry ................................................ 46

5.7 Secondary ion mass spectrometry ................................................... 50

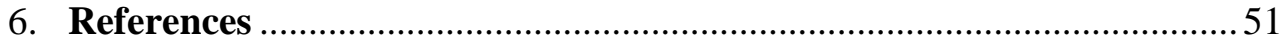

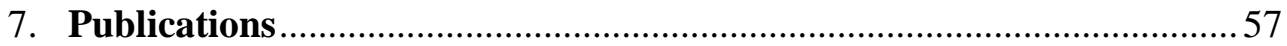

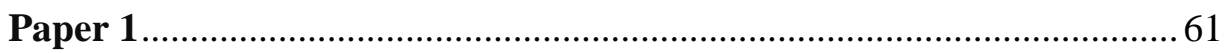

Low thermal resistance of a $\mathrm{GaN}$-on-SiC transistor structure with improved structural properties at the interface

\section{Paper 2}

Impact of residual carbon on two-dimensional electron gas properties in $\mathrm{Al}_{\mathrm{x}} \mathrm{Ga}_{1-\mathrm{x}} \mathrm{N} / \mathrm{GaN}$ heterostructure

\section{Paper 3.}

Room-Temperature mobility above $2100 \mathrm{~cm}^{2} / \mathrm{V}$-s of two-dimensional electron gas in a sharp-interface $\mathrm{AlGaN} / \mathrm{GaN}$ heterostructure

Paper 4

Growth optimization of AlGaN/GaN HEMT structures on $100 \mathrm{~mm} \mathrm{SiC} \mathrm{substrates:}$

Utilizing bottom-to-top approach

\section{Paper 5}

MOCVD growth of high-mobility AlGaN/AlN/GaN heterostructures on $\mathrm{GaN}$ templates and native $\mathrm{GaN}$ substrates

\section{Paper 6}

Dispersive effects in AlGaN/AlN/GaN HEMTs with carbon-doped buffer

\section{Paper 7}

Impact of $\mathrm{AlGaN} / \mathrm{GaN}$ interface sharpness on HEMT performance 


\section{1}

\section{History and challenges}

\section{GaN-based microwave power devices}

The momentum for developments of the group-III nitride semiconductors has been escalated for a lighting revolution, since the world's first GaN-based high-efficiency high-brightness blue light emitting diode (LED) was demonstrated in 1993 by Shuji Nakamura et al [1]. Behind this great milestone were several key breakthroughs to pave the way. One biggest problem for growth of III-nitride materials has been no/low availability of native substrates. This was overcome with the development of the lowtemperature buffer layer growth on sapphire substrates in metalorganic chemical vapor deposition (MOCVD) process pioneered by Isamu Akasaki and Hiroshi Amano, which remarkably improved the crystalline quality of GaN epitaxial layers [2]. Nevertheless, back to the days as the nitride researchers were exalted by the breakthroughs of the IIInitrides for solid state lighting, it was more or less the same time that another important property about wide-bandgap GaN and its alloy with AlN was discovered, which eventually opened up a new application for the wide-bandgap III-nitride semiconductors; microwave power devices. 
In 1992, M. Asif Khan et al first reported the observation of a two-dimensional electron gas (2DEG) in MOCVD-grown AlGaN/GaN heterojections with promising electron properties [3]. This news together with the simulation results [4] that predict high peak velocity, high saturation velocity, and high electron mobility in GaN started to make the $\mathrm{AlGaN} / \mathrm{GaN}$ heterostructures attractive for microwave and millimeterwave devices and thus to spur more investigations to see its potential. After $\mathrm{SiC}$ substrates were introduced to the epitaxial system, substantial progress both in material and device technologies was made [5][6]. Firstly, the room-temperature 2DEG mobility was improved from $\sim 600$ above $1400 \mathrm{~cm}^{2} / \mathrm{V}$-s thanks to the much lower inplane lattice mismatch between GaN-on-SiC (3.4\%) than GaN-on-sapphire (16\%), which alleviated the mosaic growth of $\mathrm{GaN}$. This result also made the heterostructure become the basis for the epitaxial structure of high electron mobility transistors (HEMTs). Secondly, an AlGaN/GaN based transistor structure grown on SiC showed that the maximum dissipated DC power was more than three times higher than in similar devices grown on sapphire, and also achieved stable performance at elevated temperature up to $250{ }^{\circ} \mathrm{C}$. This is primarily due to the high thermal conductivity of $\mathrm{SiC}$ substrates. Since then, $\mathrm{GaN}$ on $\mathrm{SiC}$ has been demonstrated as a very competitive epitaxial platform for premium microwave and millimeter-wave power devices with a wide operation temperature range. Finally, as the charge control and mechanism in $\mathrm{AlGaN} / \mathrm{GaN}$ heterostructures became more clear in early 2000, another superior property of $\mathrm{AlGaN} / \mathrm{GaN}$ heterostructures was revealed; the ability to obtain 2DEG with a very high sheet carrier density $\left(1.0 \sim 2.0 \times 10^{13} \mathrm{~cm}^{-2}\right)$ without intentional doping. This density is several times higher as compared to the one in $\mathrm{AlGaAs} / \mathrm{GaAs}$ hetrostructures.

With all properties mentioned above, the typical characteristics of wide-bandgap semiconductors like high breakdown field, high thermal conductivity and high temperature stability are also beneficial for device performance in high-power and high-frequency applications, such as the microwave power amplifiers used in military radar systems, the transmitter power amplifiers used in communication base stations and high-voltage converters and rectifiers used for automotive and aircraft industries [7]. As a result of intensive developments driven by these huge potential markets, AlGaN/GaN HEMTs started to be available as commercial-off-the-shelf devices in 2005.

Numerous advancements of wide-bandgap semiconductor technology for highfrequency power devices have been achieved over the last decade. For the power aspect, a record power density of $9.8 \mathrm{~W} / \mathrm{mm}$ at $8 \mathrm{GHz}$ for an AlGaN/GaN HEMT device grown on a $\mathrm{SiC}$ substrate was demonstrated in 2001, which is about 10 times higher than GaAs-based HEMTs [8]. And state-of-the-art power levels have continued 
being pushed higher, to total output powers of $800 \mathrm{~W}$ at $2.9 \mathrm{GHz}$ and over $500 \mathrm{~W}$ at $3.5 \mathrm{GHz}$ for instance [9][10]. For the frequency aspect, the focus has been put on the scaling technology in device fabrications together with novel ultra-thin-barrier heterostructure designs enabled by AIN and InAIN materials [11][12], and the state-ofthe-art cut-off frequency has already exceeded $450 \mathrm{GHz}$ in GaN HEMT devices [13]. For the cost aspect, the thermally compromised GaN-on-Si epitaxial platform has been anticipated to provide a good ratio of performance over cost for low-power microwave devices [14]. Plenty efforts have been poured into the strain engineering and the growth optimization to overcome the large differences in lattice constants, and thermal expansion coefficients between $\mathrm{GaN}$ and $\mathrm{Si}$, improving the crystalline quality of $\mathrm{GaN}$ based epitaxial structures [15][16]. Now good-quality $\mathrm{GaN}$ can be realized on $\mathrm{Si}$ substrates [17] and the development is moving forward to the growth on large-size wafers $(\geq 150 \mathrm{~mm})[18]$.

Though the GaN HEMT technology is progressing rapidly, some remaining material issues that limit device performance and cause device temporary degradation or permanent failures, as listed below, need to be improved or solved before its competitive advantages can be fully exploited.

1. High density of structural defects at the GaN/foreign substrate interface:

$\rightarrow$ Self-heating due to high thermal resistance at the $\mathrm{GaN}$-foreign substrate interface.

2. Existence of acceptor-like defects and impurities in the proximity of the 2DEG channel:

$\rightarrow$ Current collapse/dispersion under high-field stress and/or during highfrequency operation.

3. Non-optimized impurity distributions in $\mathrm{GaN}$ buffer layer:

$\rightarrow$ Leakage current / low breakdown voltage.

4. High density of threading dislocations:

$\rightarrow$ Leakage current / low breakdown voltage, gate lagging, trapping. 


\section{Properties of III-nitrides}

\subsection{Crystal structure}

Two crystal structures exist in III-nitrides, either cubic zincblende or hexagonal wurtzite lattice structures. The zincblende structure is only obtained under some extreme growth conditions, e.g. at very low temperature growth, under III-rich ambient, and subject to high strain, so that it is regarded as a metastable phase. The hexagonal wurtzite structure is very stable and most commonly seen for III-nitrides. All of the as-grown III-nitride materials studied in this thesis were formed in the wurtzite structure, thus the further introduction will be focused on this crystal structure and its consequent effects.

An ideal wurtzite structure consists of two hexagonal close packed (hcp) lattices interpenetrating each other by a shift of $3 c_{0} / 8$, and exhibits the relationship of $c_{0} / \mathrm{a}_{0}=\sqrt{8 / 3} \cong 1.633$, where $\mathrm{a}_{0}$ and $c_{0}$ are lattice constants as shown in Fig. 1(a). When going down to the basis of the crystal structure, one can find that the fundamental building block for wurtzite III-nitrides is a tetrahedral, where each groupIII atom is bound to four nitrogen atoms, and vice versa. However, the ideal wurzite crystal structure does not exist in any III-nitrides! This is one of the important intrinsic features for the III-nitrides. The non-ideality of the crystal is as a result of the 
imperfect tetrahedral symmetry as shown in Fig. 1(b), where the bond angle $\alpha$ between the [0001]-oriented bond and any other bonds is smaller than the ideal angle of $109.5^{\circ}$, leading to $\alpha<\beta$ and $c_{0} / \mathrm{a}_{0}<\sqrt{8 / 3}$. Among the III-nitrides, AlN has the smallest degree of the bond angle $\alpha, \sim 108.2^{\circ}$, indicating that its crystal deforms the most [19].

(a)

(b)
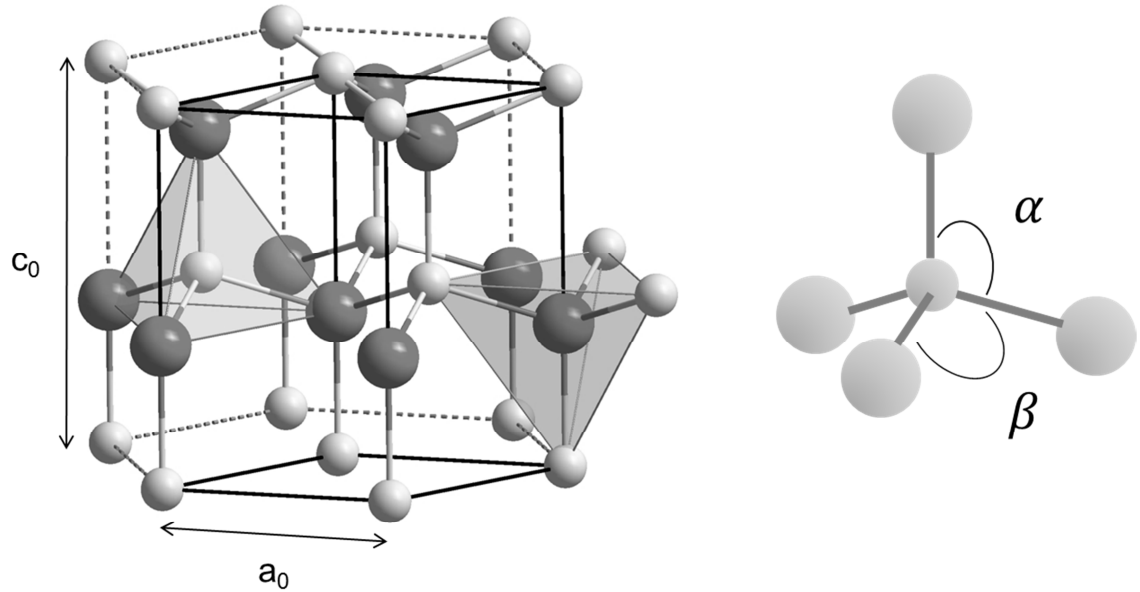

Figure 1. (a) The wurtzite crystalline structure in a binary compound. (b) A tetrahedral with the characteristic angels, $\alpha$ and $\beta$. In an ideal tetrahedral, $\alpha=\beta=109.5^{\circ}$.

Moreover, the wurtzite lattice lacks inversion symmetry along the $\mathrm{c}$ direction, resulting in a polar characteristic of the atomic configurations, which means the inversion of the group-III atoms are not themselves but nitrogen atoms, and vice versa. Therefore, an ideal wurtzite crystal oriented along the c direction shows two different atomic terminations at each side; the (0001) surface is terminated with the group-III atoms and typically referred as the $\mathrm{Ga}$, In or $\mathrm{Al}$ face/polarity, and the $(000 \overline{1})$ surface is terminated with $\mathrm{N}$ atoms and referred as the $\mathrm{N}$ face/polarity. To be more precise, the polarity is determined by the direction of the bonds between group-III atoms and $\mathrm{N}$ atoms, not necessarily by the type of the atom terminated at the surface [20].

To specify the various crystal surfaces, planes and directions of the hexagonal wurtzite III-nitrides, four-index Miller notation ( $h k i l$ ), where $i=\overline{h+k}$, is usually adopted. The overline is used to indicate a negative quantity. There are four standard notations distinctively used as follows: 
(hkil) denotes one specific plane or surface

$[h k i l]$ denotes one specific direction

$\{h k i l\}$ denotes equivalent planes or surfaces by the symmetry of the lattice

$<h k i l>$ denotes equivalent direction by the symmetry of the lattice

Fig. 2(a) and (b) show the lattice parameters and some major planes and directions. The $\langle 0001\rangle$, $\langle 11 \overline{2} 0\rangle$, and $\langle 1 \overline{1} 00\rangle$ directions are called $\mathrm{c}$, a, and $\mathrm{m}$ directions, respectively.
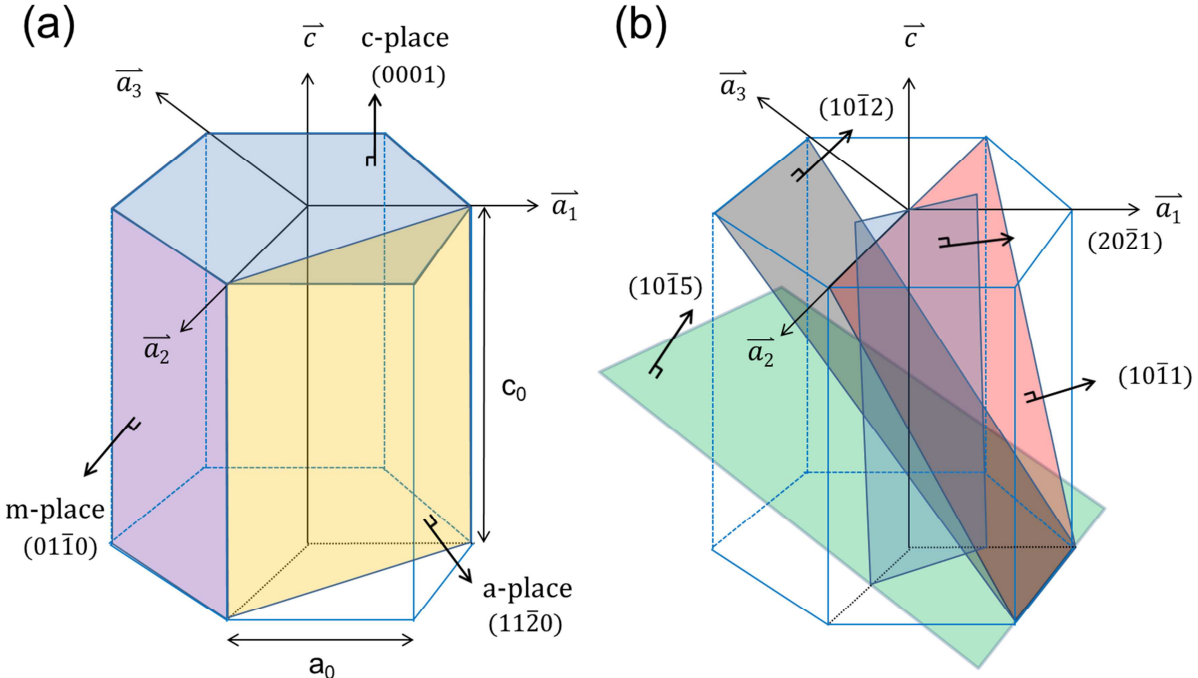

Figure 2. (a) and (b) Some important crystal planes in a hexagonal structure including crystallographic axes.

\subsection{Bandgap property and engineering}

For a semiconductor, the bandgap can be categorized into two types, either direct bandgap or indirect bandgap. The former one depicts that the conduction band minimum and the valance band maximum of a semiconductor are aligned in the reciprocal space where $\mathrm{k} \cong 0$. The latter one depicts that in case when the conduction band minimum is located at $\mathrm{k} \neq 0$, the electron-hole recombination cannot occur unless a third particle, phonon, is involved in the process. Schematic band diagrams of a direct bandgap and an indirect bandgap are illustrated in Fig. 3. All III-nitride 
semiconductors have direct bandgaps. This property makes them highly attractive and competent in optoelectronics because the radiative electron-hole recombination via a nearly vertical transition in $\mathrm{k}$ space is more efficient than in materials having indirect bandgaps.

The bandgaps of InN, GaN and AlN are 0.7, 3.5, and $6.2 \mathrm{eV}$, respectively [21]. In principle, a wide range of bandgap tuning from 0.7 to $6.2 \mathrm{eV}$ is permitted by means of adjusting the composition of a ternary or a quadrary alloy formed by the III-nitrides. The modified Vegard's law can be used to determine the band gap of an III-nitride alloy with a given fractional composition with a correction bowing factor, $C$. For a ternary system,

$$
E_{g}\left(A_{1-x} B_{x}\right)=(1-x) E_{g}(A)+x E_{g}(B)-x(1-x) C,
$$

(a)

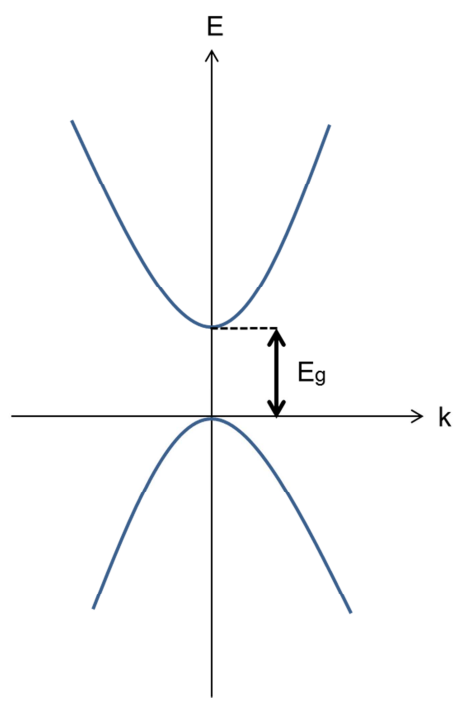

(b)

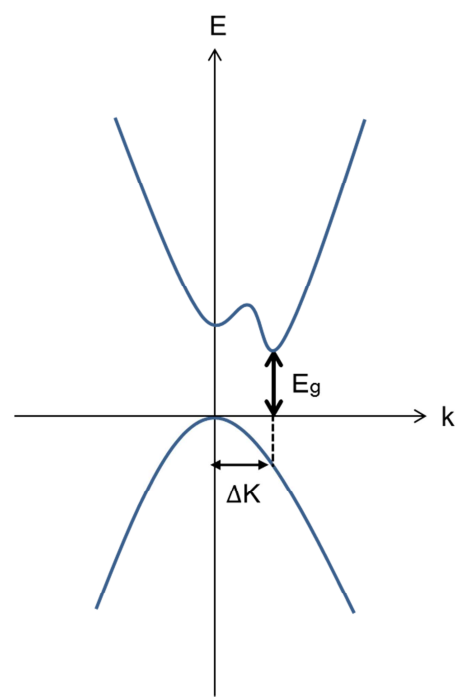

Figure 3. Schematic pictures of (a) direct and (b) indirect bandgaps in semiconductors. 


\subsection{Built-in polarizations}

All III-V compound semiconductors have covalent atomic bonds that also exhibit a certain degree of iconicity. In the III-nitirdes the atomic bonds have a particular high degree of iconicity, due to the fact that the small-radius nitrogen atoms are very electronegative as a result of its tightly bound electrons. Therefore, the shared electrons between the nitrogen and the III-element tend to be displaced closer to the nitrogen atom, leaving the III-element more positive, thus an electron dipole is automatically formed by the polar-like charge distribution.

In an ideal tetragonal bonding configuration, the electron dipoles will cancel each other. However, as mentioned earlier, the building block for the III-nitrides is a nonideal tetrahedron and is deformed in a way that the in-plane components of the electron dipoles are cancelled by each other but the component along the [0001] direction cannot be fully compensated. Thus, the net dipole for each tetrahedron is aligned parallel to the [0001] direction and its vector direction points from the nitrogen atom to the III-element. This is the origin of the polarization, and is called spontaneous polarization.

Since the III-nitrides lack inversion symmetry along the [0001] direction, and the positive and negative charges of the dipoles are screened by the opposite charges in their proximity inside the material, the unscreened charges with different signs but same magnitude are thus revealed at the two sides of the crystal boundaries along the [0001] direction, as illustrated in Fig. 4. The unscreened charges are called polarization induced sheet charges, the distribution of which is analogous to a simple parallel-plate capacitor. Therefore, the measure of the polarization is defined as charges per unit area.

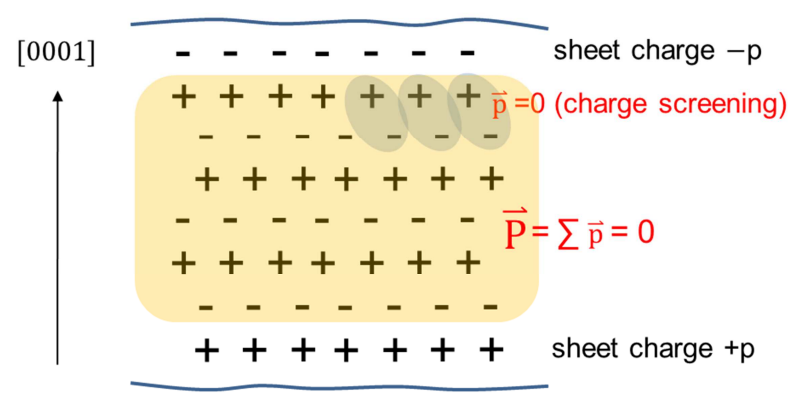

Figure 4. Schematic of the net dipole moment in a wurtzite structure. 
In addition to the intrinsic spontaneous polarization, there is the other polarization called piezoelectric polarization, resulting from the further deformation of the tetrahedron structure by the stress applied to the wurtzite crystal. If the stress is introduced to the crystal in two directions ( $x-y)$ along its surface, the crystal is biaxially strained. Two types of the strain are illustrated in Fig. 5. When the c-plane oriented crystal is under a biaxial tensile strain, the bond angle $\alpha$ becomes smaller. Thus, the direction of the spontaneous and piezoelectric polarizations is parallel. While under a biaxial compressive strain, the bond angle $\alpha$ becomes larger so that the direction of the spontaneous and piezoelectric polarizations turns to be opposite. The total polarization inside the III-nitrides is accordingly as the sum of the spontaneous $\left(\vec{P}_{s p}\right)$ and piezoelectric $\left(\vec{P}_{p z}\right)$ polarizations:

$$
\vec{P}_{\text {total }}=\vec{P}_{s p}+\vec{P}_{p z}
$$

Table I summaries the lattice parameters of $\mathrm{AlN}, \mathrm{GaN}$ and $\mathrm{InN}$ and their spontaneous polarization strength [19].

(a)

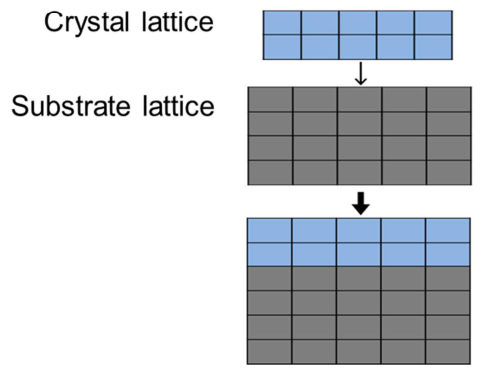

(b)

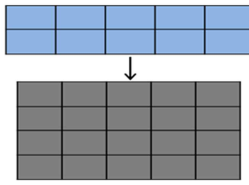

$\checkmark$

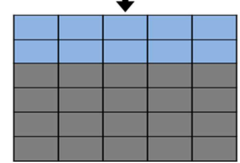

Figure 5. The crystal deposited on the substrate is under (a) tensile strain, (b) compressive strain.

Table I. The lattice parameters of AlN, GaN and InN and their spontaneous polarization strength, $\overrightarrow{\boldsymbol{P}}_{s p}=P_{s p}[0001]$

\begin{tabular}{|c|c|c|c|}
\hline Wurtize & AIN & GaN & InN \\
\hline $\mathrm{a}_{0}(\AA)$ & 3.112 & 3.189 & 3.54 \\
\hline $\mathrm{c}_{0}(\AA)$ & 4.982 & 5.185 & 5.705 \\
\hline$c_{0} / \mathrm{a}_{0}$ & 1.601 & 1.627 & 1.612 \\
\hline$P_{s p}\left(\mathrm{C} / \mathrm{m}^{2}\right)$ & -0.081 & -0.029 & -0.032 \\
\hline
\end{tabular}




\section{Fundamentals of GaN-based HEMT structures}

\subsection{Properties of GaN}

Besides the direct bandgap, GaN has many other superior properties, like high robustness, high chemical stability, high electron mobility, high thermal conductivity, and high breakdown field. A comparison of the material properties of GaN with other classic semiconductors is listed in Table II. These properties make GaN-based devices competent to work in harsh conditions, like high temperature, high field, and to deliver high-power at microwave frequencies. One electronic device typically used in the abovementioned applications is the high electron mobility transistor, the details of which will be described in the coming section. 
Table II. Properties of $\mathrm{GaN}$ and other semiconductors at room temperature [22][23][24].

\begin{tabular}{|c|c|c|c|c|c|}
\hline Material & $\begin{array}{c}\text { Bandgaps } \\
\text { (eV) }\end{array}$ & $\begin{array}{l}\text { Electron } \\
\text { mobility } \\
\left(\mathrm{cm}^{2} / \mathrm{V}-\mathrm{s}\right)\end{array}$ & $\begin{array}{c}\text { Saturation } \\
\text { velocity } \\
(\mathrm{cm} / \mathrm{sec})\end{array}$ & $\begin{array}{c}\text { Thermal } \\
\text { conductivity } \\
\text { (W/mm-K) }\end{array}$ & $\begin{array}{c}\text { Breakdown } \\
\text { field } \\
(\mathrm{V} / \mathrm{cm})\end{array}$ \\
\hline GaN & 3.45 & 1250 & $2.5 \times 10^{7}$ & 260 & $5.0 \times 10^{6}$ \\
\hline Si & 1.12 & 1500 & $1.0 \times 10^{7}$ & 150 & $0.3 \times 10^{6}$ \\
\hline GaAs & 1.43 & 8500 & $1.0 \times 10^{7}$ & 46 & $0.4 \times 10^{6}$ \\
\hline $4 H-S i C$ & 3.26 & 1000 & $2.0 \times 10^{7}$ & 490 & $2.2 \times 10^{6}$ \\
\hline $6 H-S i C$ & 3.03 & 500 & $2.0 \times 10^{7}$ & 490 & $2.5 \times 10^{6}$ \\
\hline
\end{tabular}

\subsection{GaN-based high electron mobility transistor}

\subsubsection{Epitaxial structures}

In 1992, Asif Kahn et al reported the first confirmation of high-mobility twodimensional electron gas forming in the $\mathrm{Ga}$-face $\mathrm{Al}_{\mathrm{x}} \mathrm{Ga}_{1-\mathrm{x}} \mathrm{N} / \mathrm{GaN}$ heterostructure [3], which serves as the basis of the epitaxial structure for high electron mobility transistors (HEMTs). Since then, the growth of AlGaN/GaN HEMT epitaxial structures has been intensively studied and advanced on various substrates, including sapphire, $\mathrm{SiC}, \mathrm{Si}$ and bulk GaN substrates, using growth techniques such as molecular beam epitaxy (MBE) or metalorganic chemical vapor deposition (MOCVD). Other different HEMT heterostructures were also proposed and successfully demonstrated, like using a thin AlN or InAlN barrier layer, or N-face HEMTs [25].

In this study, all the HEMT epitaxial structures were grown on $\mathrm{Si}$-face $\mathrm{SiC}$ substrates or Ga-face GaN substrates, which consequently lead to metal-face HEMT structures. Thus, the following content will be focused on the material systems with $\mathrm{Ga}(\mathrm{Al})$ polarity. 


\subsubsection{Origin of the two-dimensional electron gas}

The phenomenon of the high-density two-dimensional electron gas (2DEG) forming in the strained or pseudomophic III-nitride heterostructures with the wurtzite crystal structure grown in the [0001] direction was intensively studied by different research groups in the late 1990s and the early 2000s. Many different formation mechanisms were proposed, and in particular, there are two models having been the most accepted. One is based on the polarization induced effect, and the other is based on a charge transfer from surface states.

The polarization induced effect was proposed by O. Ambacher et al, in which the formation of $2 \mathrm{DEG}$ is considered a consequence of interface charges induced by spontaneous and piezoelectric polarization effects [26]. As described previously, the cplane grown wurtzite III-nitride materials possess the polarization induced sheet charges at the two sides of the crystal boundaries along the [0001] direction, and the III-element is more positive than nitrogen due to the uneven electron distribution in the bonding configuration. Therefore, for the crystals with the metal-face polarity, negative polarization induced sheet charges would appear at the upper side of the crystal boundary, while positive ones show at the other side.

Now, considering a c-plane oriented $\mathrm{AlGaN} / \mathrm{GaN}$ heterstructure with $\mathrm{Ga}(\mathrm{Al})$ polarity, the fixed polarization induced sheet charges at the interface would be the sum of the positive sheet charges at the bottom of the $\mathrm{AlGaN}$ and the negative sheet charges at the top of the GaN, see Fig. 6(a). As the author deduced, if the net polarization induced sheet charges at the interface is positive, free electrons will be induced to compensate the fixed positive polarization induced sheet charges leading to the formation of 2DEG with a sheet carrier concentration $n_{s}$ located within the GaN, providing that the conduction band offset between the $\mathrm{AlGaN}$ and the $\mathrm{GaN}$ is reasonably high to make the triangular quantum well at the interface drop below the Fermi level. This 2DEG formation mechanism also predicted the 2DEG to be localized at the lower AlGaN/GaN and upper GaN/AlGaN interfaces for Ga- and N-face GaN/AlGaN/GaN heterostructures, respectively, as shown in Fig. 6(b). 
(a)

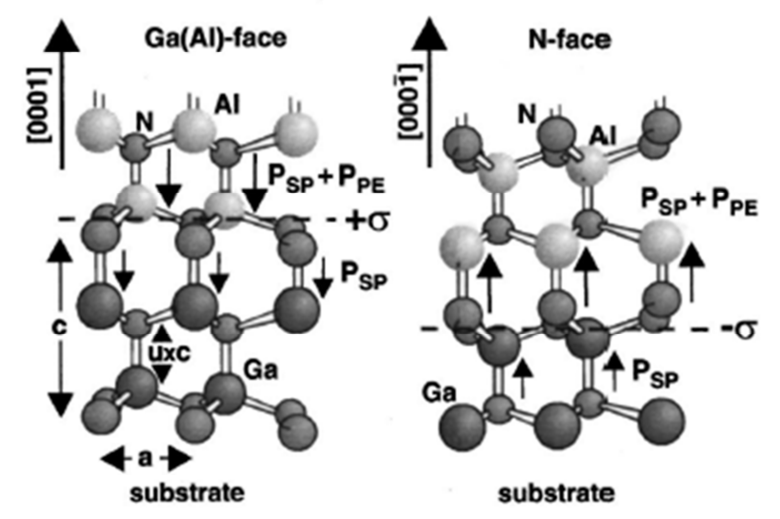

(b)

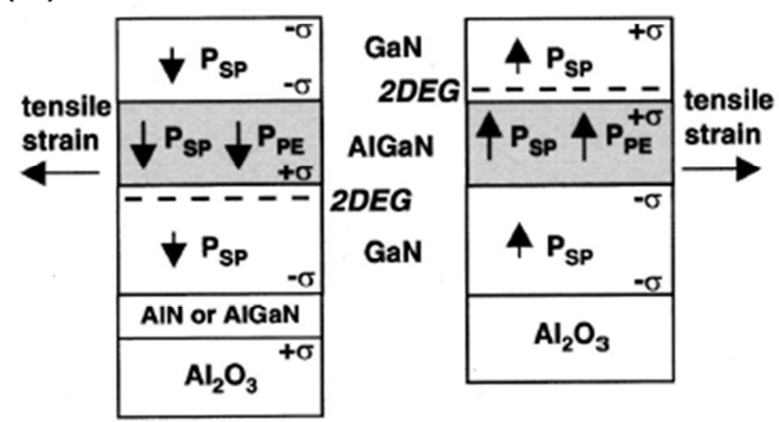

Figure 6. (a) Crystal structure, polarization induced bound sheet charge, piezoelectric and spontaneous polarization, of pseudomorphic AlN/GaN heterostructures with $\mathrm{Ga}(\mathrm{Al})$-face or $\mathrm{N}$-face polarity. (b) Spontaneous polarization, piezoelectric polarization bound interface charges, and 2DEGs in pseudomorphic GaN/AlGaN/GaN heterostructures with Ga-face or N-face polarity. Reprinted from O. Ambacher, B. Foutz, J. Smart, J. R. Shealy, N. G. Weimann, K. Chu, M. Murphy, A. J. Sierakowski, W. J. Schaff, and L. F. Eastman, R. Dimitrov, A. Mitchell, and M. Stutzmann, Journal ot Applied Physics 87, 334 (2000)

Moreover, the orientation of the piezoelectric and spontaneous polarization was found parallel in the case of tensile strained AlGaN layers, which is valid for all thin AlGaN barrier layers pseudomorphically grown on relaxed $\mathrm{GaN}$ buffer layers regardless the polarity. Thus, increasing the $\mathrm{Al}$ content in the $\mathrm{AlGaN} / \mathrm{GaN}$ heterostructure would enlarge both the piezoelectric and spontaneous polarization, giving rise to higher 2DEG density. Furthermore, it was also found that the thickness of the AlGaN layer and GaN cap layer can influence the 2DEG density. To illustrate this point more 
clearly, it is useful to derive $n_{s}$ using Poisson equation based on a simple electrostatic analysis [27], which yields

$$
n_{S}=\frac{1}{1+\frac{d_{G a N ~ c a p}}{d_{A l G a N}}}\left(\frac{\sigma^{p o l}}{e}-\frac{\varepsilon \varepsilon_{0}}{d_{A l G a N}}\left(e \emptyset_{B}+E_{F}\right)\right),
$$

where $d_{\text {GaN cap }}$ and $d_{\text {AlGaN }}$ are the thicknesses of the top GaN cap and the AlGaN barrier layers, respectively; $\sigma^{p o l}$ is the polarization-induced charge density determined by the difference in the total polarization within the $\mathrm{AlGaN}$ and $\mathrm{GaN}$ layers; $e \emptyset_{B}$ is the Schottky surface barrier height; $E_{F}$ is the Fermi level position with respect to the $\mathrm{GaN}$ conduction-band edge in the GaN buffer. As a result of Eq. (3), one can see that 2DEG density is increased with a thicker AlGaN layer but is reduced with a thicker GaN cap layer.

Although the 2DEG formation could be well explained by the polarization induced effect, the proposed mechanism did not account for the source of the free electrons. To address this issue, J. P. Ibbetson et al suggested that the source of the free electrons forming the 2DEG must come from the ionized donors in the AlGaN barrier plus the ionized donor-like states on the surface [28]. This proposal was based on the fact (a) the AlGaN/GaN heterostructure as a whole must be charge neutral in the absence of an externally applied field and (b) the polarization-induced charges constitute a dipole whose net contribution to the total space charge is exactly zero; thus, a charge balance equation can be obtained as following:

$$
\sigma_{\text {surface }}+\sigma_{A l G a N}+\sigma_{p}+\left(-\sigma_{p}\right)+\left(-q n_{s}\right)=0
$$

where $\sigma_{\text {surface }}$ is the charge due to the ionized donors; $\sigma_{A l G a N}$ is the integrated sheet charge due to the ionized donors; $\sigma_{p}$ and $-\sigma_{p}$ are the fixed polarization-induced charges at the $\mathrm{AlGaN} / \mathrm{GaN}$ interface and the surface, respectively; $-q n_{s}$ is the negative sheet charge due to the $n_{s}$ electrons in the 2DEG.

which leads to

$$
q n_{s}=\sigma_{\text {surface }}+\sigma_{\text {AlGaN }}
$$

In the case of a truly undoped AlGaN barrier, Eq. (5) states that any 2DEG electrons come from donor-like surface states. Later, an X-ray photoelectron spectroscopy study of the AlGaN surface revealed that the donor-like surface states are $\mathrm{N}$-vacancy related [29]. Another point made in this model is that the role of the positive fixed polarization induced changes at the $\mathrm{AlGaN} / \mathrm{GaN}$ interface is to merely facilitate the transfer of free electrons from the surface and/or the AlGaN bulk into the potential well at the interface when the donor-like states are ionized. 


\subsubsection{Transport properties of 2DEG}

It was confirmed that the low-field electron mobility in bulk GaN would never go as fast as the one in bulk GaAs, simply because the electron effective mass in GaN is about three times higher than that in GaAs. However, what makes $\mathrm{GaN}$ special here is that in the high electrical field $\mathrm{GaN}$ has a larger peak electron velocity and higher saturation velocity (velocity is the product of mobility and electrical field), which means the mobility can remain relatively high in the high field without degradation. This property makes GaN very suitable for microwave power devices. Consequently, enormous computational and experimental efforts have been made to understand the behavior of the electron transport in the GaN-based HEMT structures and to explore its limiting factors in different regimes of the ambient temperature and the electron concentration. The details of the computational analysis of the transport properties go beyond the scope of the work in this thesis, so that only the important results brought from the computation and experimental observation are summarized here. They are presented in a way to highlight the influence of each major scattering mechanism on the electron mobility in the HEMT structures as follows:

(a) Acoustic and optical photons:

This is the dominant scattering mechanism in the high temperature regime $(>100 \mathrm{~K})$, which ultimately limits the 2DEG mobility, provided that other scattering factors are reasonably insignificant. In this case, the results from the computations [30] and the experiments [31][32] show in good agreement to each other that the room-temperature 2DEG mobility is eventually limited below $2500 \mathrm{~cm}^{2} / \mathrm{V}-\mathrm{s}$.

(b) Alloy disorder:

Since AlGaN is a ternary alloy material, alloy disorder scattering is expected to occur in the $\mathrm{AlGaN} / \mathrm{GaN}$ interface. The effect is especially pronounced when a high 2 DEG density $\left(>7 \times 10^{12} \mathrm{~cm}^{-2}\right)$ is induced and poor carrier confinement in the interface is established so that part of the electron wave function penetrates into the AlGaN barrier layer. Under this circumstance, the room-temperature 2DEG mobility is further limited, usually below $1600 \mathrm{~cm}^{2} / \mathrm{V}$-s [33][34]. To overcome this issue, L. Hsu and W. Walukiewicz was the first to suggest that inserting a very thin layer of AIN (only a few angstroms thick) into the $\mathrm{AlGaN} / \mathrm{GaN}$ heterostructure can confine the electrons nearly exclusively to binary compounds and completely eliminate the alloy scattering [30]. This proposal was based on their calculations that the penetration depth of electrons into AlN would be only $3 \AA$. Just few years later, room-temperature $2 \mathrm{DEG}$ 
mobility above $2000 \mathrm{~cm}^{2} / \mathrm{V}$-s was then realized for the first time using the $\mathrm{AlGaN} / \mathrm{AlN} / \mathrm{GaN}$ heterostructure as proposed [31].

\section{(c) Interface roughness}

This scattering mechanism is less pressing nowadays, because the surface of the modern MBE- and MOCVD-grown GaN thick epilayers typically exhibits smooth atomic steps with root-mean-square roughness lower than $0.5 \mathrm{~nm}$. However, we did observe that a low-roughness $\mathrm{AlGaN} / \mathrm{GaN}$ heterostructure showed particularly low 2DEG mobility $\left(<500 \mathrm{~cm}^{2} / \mathrm{V}-\mathrm{s}\right)$ due to a lowdimensional-grain-like morphology.

\section{(d) Residual impurities}

The concentration of the typical residual impurities like $\mathrm{O}, \mathrm{Si}$, and $\mathrm{C}$ in unintentionally-doped GaN is usually below $1 \times 10^{17} \mathrm{~cm}^{-3}$. The 2DEG mobility would not be severely affected. Nevertheless, it should be noted that carbon is an acceptor-like impurity, which means it would trap electrons [35]. Therefore, once the carbon concentration in $\mathrm{GaN}$ is increased, one can expect the electron mobility to be reduced.

\section{(e) Threading dislocation}

Since the density of this type of structural defect in heteroepitaxially grown GaN layers is still high $\left(>1 \times 10^{8} \mathrm{~cm}^{-2}\right)$ and it pierces the 2DEG, it is considered as a factor which could influence the transport. It was shown earlier that this scattering mechanism is pronounced only in the low-temperature $(<<300 \mathrm{~K})$ and low-2DEG-density $\left(<2 \times 10^{12} \mathrm{~cm}^{-2}\right)$ regime [36]. However, it was recently observed that the room-temperature 2DEG mobility was degraded with increased dislocation density $\left(>1 \times 10^{10} \mathrm{~cm}^{-2}\right)$ for the HEMT heterostructures with 2DEG density above $1 \times 10^{13} \mathrm{~cm}^{-2}$ [37].

\section{(f) Coulomb scattering}

This transport limiting factor is due to ionized impurity, and it only occurs in low-2DEG-density regime resulting in a typical characteristic that the mobility is increased with higher 2DEG density [38]. 


\section{4}

\section{MOCVD growth of GaN-based HEMT structures}

\subsection{Fundamentals of the MOCVD process}

MOCVD stands for metal-organic chemical vapor deposition, which has been considered the most versatile material growth technique. It is also referred as metalorganic vapor phase epitaxy (MOVPE) as only the single-crystalline epitaxial growth is concerned. This growth technique features with the strength in high flexibility of materials, high purity, high growth rates, high uniformity, and capability for abrupt interfaces, large-scale production, selective growth, and in-situ monitoring. The research for MOCVD was started in the late 1960s by the pioneers Manasevit and his coworkers [39]. The development was being accelerated over time. Until the late 1990s, MOCVD became the leading growth technique as the issues related to purity and the inherent limits on interface abruptness were largely improved. Since then, it has been widely adopted in the semiconductor industry, particularly of the III-nitrides, to produce epitaxial device structures for a variety of applications, such as lightemitting diodes, solar cells, field-effect transistors and so forth. In this thesis, a MOCVD tool was used for epitaxial growth of GaN-based HEMT structures, more details of which will be described later. 
The MOCVD process is basically a CVD process specified with the use of metalorganic compounds for supplying the group-III elemental sources. For MOCVD growth of III-V semiconductor compounds, a hydride gas containing the group-V elements, such as $\mathrm{AsH}_{3}$ or $\mathrm{NH}_{3}$, is commonly used. In a very general description, CVD is a vapor-to-solid process where chemical reactions take place in the vapor phase of the supplied precursors leading to the formation of a solid material deposited on a substrate material [40]. The chemical reactions are facilitated by introducing some external energy, such as heat, plasma, ion-beam, and photons, for pyrolysis of the precursors and assistance to the reactions. Although CVD involves highly complex processes, it can be simplified into several key steps as follows and illustrated in Fig. 7:

1. Transport of precursors to the growth zone;

2. Gas-phase reactions of precursors in the growth zone producing reactive intermediates and by-products;

3. Mass transport of reactants to the substrate surface;

4. Adsorption of reactants on the substrate surface;

5. Surface diffusion to growth sites;

6. Nucleation, and surface reactions leading to solid formation;

7. Desorption and mass transport of decomposed fragments away from the growth zone;

8. Exhaust to the pumping system.

1. Gas flow

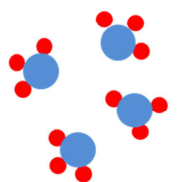

2. Gas phase reaction

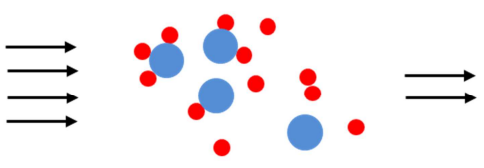

3. Mass transport

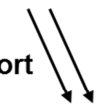

Substrate
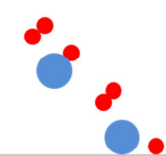

4. Surface adsorption 5 . Surface diffusion

8. Exhaust

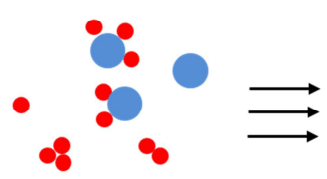

7. Desorption

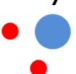

6. Growth

6. Nucleation

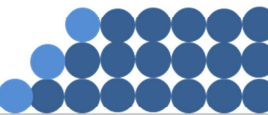

Figure 7. Illustration of the CVD process. 
Among the key steps mentioned above, mass transport is the only one regarding the hydrodynamic aspect of CVD, which depends more on the reactor configurations and total system pressure.

Considering reactor configurations, it is always desirable to design MOCVD systems in a way to make gas flows working in a laminar flow regime, to achieve better growth control and uniformity. Laminar flow can be considered as a fluid flowing in parallel layers and having no disturbance between layers [41], which can be characterized by Reynolds number, a quantitative measure used to determine different flow regimes when a fluid is in motion relative to a surface. Reynolds number $(R e)$ is defined as the ratio of the inertial forces to the viscous forces and is expressed by:

$$
R e=\frac{\rho v^{2} L^{2}}{\mu v L}=\frac{\rho v L}{\mu},
$$

where $\rho$ is the density of the fluid, $v$ is the mean velocity of the fluid, $L$ is the travel length of the fluid, and $\mu$ is the dynamic viscosity of the fluid.

For the value of Reynolds number $<2000$, the gas flow is within a laminar flow regime. As the value of Reynolds number $>3000$, the laminar flow transits to a turbulent flow, where the gas flow is chaotic heading in mixing directions leading to non-uniform deposition profile.

The importance of the laminar flow regime can be elucidated further with formation of a boundary layer where the reactants diffuse from gas phase to the substrate due to the reactant concentration gradient [42]. The concept of formation of the boundary layer is based on the viscous effect of parallel flows over a flat plane. The velocity of the parallel gas flows is gradually reduced in the proximity of the flat plane and becomes 0 at the flat plane (substrate or reactor walls) due to friction force at the surface, as illustrated in Fig. 8. Its thickness $\delta(x)$ is defined from the flat plane perpendicularly up to the level where the gas velocity is nearly equal to the initial velocity of the gas flow $\left(v_{0}\right)$, and can be calculated as follows:

$$
\delta(x)=c\left(\frac{\mu x}{\rho v_{0}}\right)^{1 / 2},
$$

where $c$ is a constant and $x$ is the flow travel distance from the start of forming boundary layer 


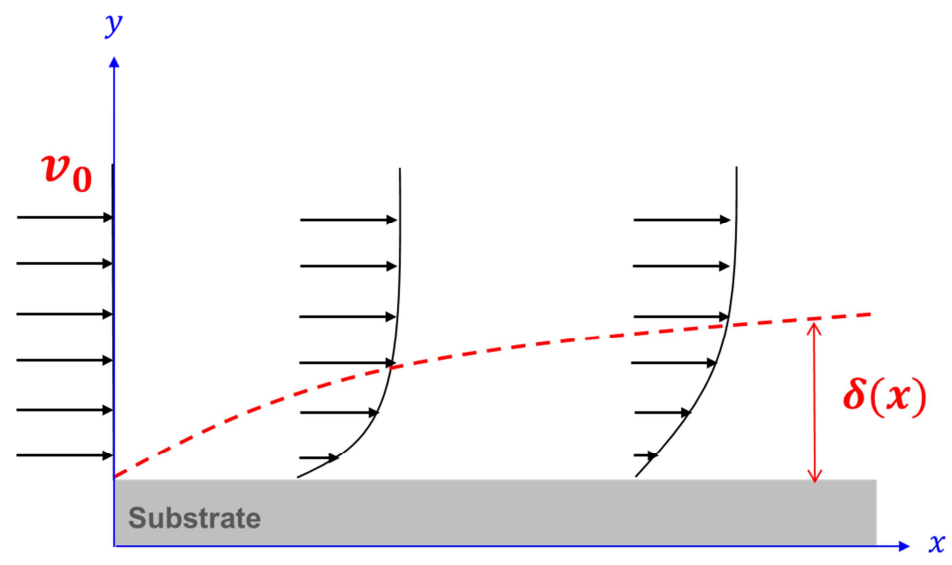

Figure 8 . Profile of the gas velocity above a substrate surface and the formation of a boundary layer with its thickness $\boldsymbol{\delta}(\boldsymbol{x})$.

We can see that the thickness of the boundary layer depends on the viscosity of the carrier gas and the gas density. In order to have a controllable growth, the boundary layer should not be too thin. Thus, one easy way to increase its thickness is to decrease the gas density, in other words, to reduce the pressure. Besides, reducing pressure has other advantages, like minimizing the turbulent flows (convective eddy current), and decreasing the number of collision of precursor molecules in the gas phase, which alleviates parasitic reactions. The latter one is particularly important since high crystalline quality of wide-band-gap materials, like GaN, AlN, and their alloy is commonly obtained at high growth temperature regime where the pre-reactions of precursors in the gas phase are greatly enhanced. Hence, low-pressure MOCVD systems are widely used for growth of the wide-bandgap III-nitride materials. 
Moreover, reducing pressure can also enhance the diffusion in the mass-transport process [43].

$$
D=D_{0} \frac{P_{0}}{P}\left(\frac{T}{T_{0}}\right)^{b},
$$

where $D_{0}, P_{0}$, and $T_{0}$ are constants, and $b$ has a value of $1.82 \sim 1.88$ for nonpolar gases. This is the semiempirical expression. If we take TMGa in $\mathrm{H}_{2}$ for example [44], the diffusion coefficient is,

$$
D\left(\frac{\mathrm{cm}^{2}}{\mathrm{~s}}\right)=\frac{2.23 \times 10^{-5} T^{1.73}}{P},
$$

where the units of $T$ and $P$ are $K$ and atm, respectively.

To understand the overall growth mechanism, studying the dependence of an important macroscopic quantity like growth rate on external parameters such as substrate temperature and flow rates of precursor can lead to some more insights [45]. The limiting factors of growth rate in different temperature regimes of a CVD process, as illustrated in Fig. 9, can be modeled by three major mechanisms: thermodynamics, mass transport and surface kinetics from high temperature to low temperature, respectively [46].

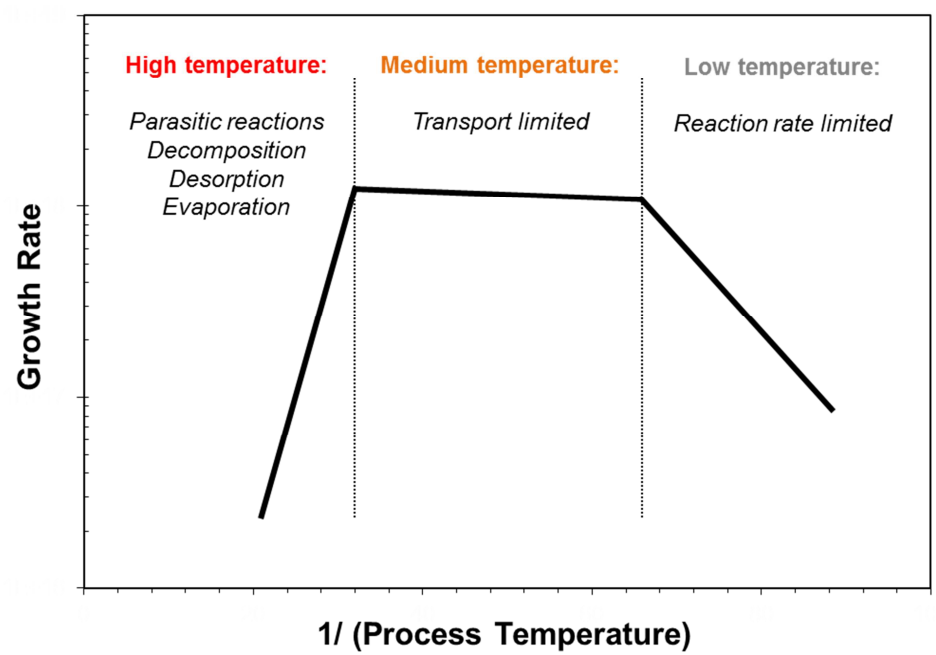

Figure 9. Three major growth regimes as function of reciprocal process temperature. 
(a) Thermodynamics governs the direction of the reactions.

Consider a CVD process as a system, which is intentionally brought to a nonequilibrium situation by changing temperature and pressure, where a high supersaturation (the chemical potential difference between vapor and solid phase) can be created. Thus, minimizing the free energy for the system in order to restore equilibrium becomes the thermodynamic driving force for growth. In this case, the created supersaturation has to be consumed, which in turn produces the solid. Therefore, increasing temperature fundamentally provides more driving force for growth, in which the growth rate is thus less thermodynamically limited. However, in the very high temperature regime, increasing temperature would significantly elevate the chemical potential of the solid, rendering a reduced supersaturation. Therefore, the growth rate is thermodynamically reduced, because desorption of the solid is taking place, too.

(b) Mass transport determines the diffusion rate of reactants from gas-phase to the substrate surface.

This occurs in medium-high-temperature growth regime, which has less dependence on temperature, but more on pressure that greatly influences the thickness of the boundary layer and diffusion coefficient as mentioned earlier. Besides, the growth rate is proportional to the flux of reactants arriving at the substrate surface. In the case for growth of the III-nitrides, the flux of the group-III precursors is typically the ratelimiting elemental source, which can be expressed,

$$
J=\frac{D\left(p^{*}-p^{S}\right)}{R T \delta_{0}},
$$

where $p^{*}$ is the input partial pressure of the group III source, $p^{s}$ is the group III partial pressure at the surface.

(c) Kinetics defines the rates of the various processes.

Growth rate is mainly limited by the reaction kinetics in the low and medium temperature regime, so that it is exponentially proportional to the reciprocal process temperature $(1 / \mathrm{T})$. The process temperature has a major influence in this regime to activate and facilitate a variety of processes, starting from pyrolysis and reactions of precursors in the gas phase, to adatom diffusion at the solid surface and the nucleation process and so forth. The activation energy of the slowest (rate-limiting) reaction process can be extracted from the slope of the curve shown in Fig. 8. However, this 
temperature regime is not suitable for growth of the wide-bandgap III-nitride materials, due to the fact poor structural quality and high incorporation of residual impurities are usually obtained.

\subsection{Hot-wall MOCVD reactor}

In this work, a horizontal hot-wall MOCVD system was employed for the growth of GaN-based HEMT structures. The hot wall concept used at Linköping Univeristy, as illustrated in Fig. 10, was originally developed for $\mathrm{SiC}$ epitaxy. In contrast to conventional cold-wall MOCVDs, where the external heat is supplied only from the underneath of substrates, the substrate in the hot-wall MOCVD system is wrapped around by a heated susceptor consisting of a bottom, walls, and a roof. Thus, the hotwall configuration enables better efficiency of cracking precursors, much wider temperature window up to $1600{ }^{\circ} \mathrm{C}$ and reduced thermal gradient in the growth zone resulting in less wafer bowing [47]. Besides, the bottom part of the susceptor hosts a cassette equipped with a gas foil rotated satellite to rotate the substrate.

The hot-wall MOCVD was commercially built with a chamber made by quartz (VP508GFR, Aixtron AB). It has a growth capacity of $3 \times 2$ ", $1 \times 3$ ", or $1 \times 4$ " wafer for each growth run. The entire system combines four major subsystems, including a heating system, a gas system, a pumping system and an exhaust system.

The heating system is based on current induction in the TaC-coated graphite susceptor using a water-cooled coil that is biased alternating in radio frequency. A pyrometer is focused in a hole at the upstream part of the susceptor to monitor the growth zone temperature and provides feedback to the system to regulate the RF power and thereby controlling the temperature. Moreover, the entire susceptor is wrapped around by a porous graphite insulation, which is constantly purged with a nitrogen flow to increase the heating efficiency. 


\section{Hot-wall MOCVD concept}

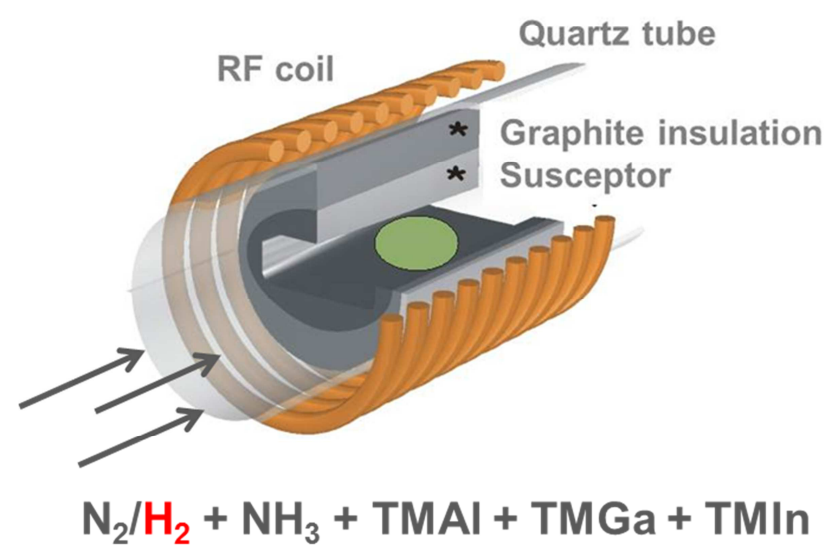

Figure 10. Configuration of the horizontal hot-wall MOCVD growth zone.

The gas system is the most complicated block in the entire system. Gas flows are precisely controlled by mass flow controllers (MFCs) and can be switched instantly between the run line (to growth zone) and the vent line (to exhaust system) through pneumatic valves to increase the abruptness in heteroepitaxy. The gas system is also equipped with different purifiers for each gas. Pressured $\mathrm{N}_{2}$ and $\mathrm{H}_{2}(\sim 2$ atm after the purifiers) are used as carrier gases to pick up the vapors of metal-organic compounds stored in stainless steel containers (bubbler) and to deliver them to the growth zone. For growth of III-nitride compound semiconductors, the group III elements are supplied from the metal-organic precursors, trimethyelgallium (TMGa, $\left.\mathrm{Ga}\left(\mathrm{CH}_{3}\right)_{3}\right)$, trimethyaluminium (TMAl, $\mathrm{Al}_{2}\left(\mathrm{CH}_{3}\right)_{6}$ ), and trimethylindium (TMIn, $\left.\operatorname{In}\left(\mathrm{CH}_{3}\right)_{3}\right)$, the vapor pressure of which is controlled by the individual bubbler bath temperature. Regarding the elemental nitrogen source, purified ammonia gas is supplied from a gas cylinder.

The pumping system consists of a mechanical pump with a throttle valve to regulate the process pressure, and a turbo pump with a back pump to evacuate residual background vapors and impurities before each growth run. With the turbo pump, the background pressure in the system can reach $5 \times 10^{-5}$ mbar within 2 hours, and $5 \times 10^{-6}$ mbar if pumped overnight.

The last block is the gas exhaust system, the so-called scrubber that handles the exhausted reaction by-products and un-reacted chemical gases with effluent treatment that neutralizes the alkaline chemicals. 


\subsection{Epitaxial growth process of GaN-based HEMT structures}

\subsubsection{Substrate choices}

The choice of substrate for growth of GaN-based HEMT structures aiming for highpower and high-frequency applications primarily depends on two critical parameters: thermal conductivity and in-plane lattice structure. A high thermal conductivity of the substrate is very desirable in the HEMT structures to alleviate the self-heating effect of the device, which considerably shortens the device lifetime and limits the device performance, but the merit of the thermal property cannot be taken without considering the extent of the substrate's lattice mismatch with GaN. Moreover, the substrate used for the HEMT applications has to be semi-insulating (SI) to prevent parallel conductions in the device. Four commonly used substrates in the HEMT epitaxial growth are listed in the Table III for comparison.

Table III. Common substrates used in GaN-based HEMT epitaxy.

\begin{tabular}{|c|c|c|c|c|}
\hline Substrate & Sapphire & Si & SiC & Bulk GaN \\
\hline In-plane lattice mismatch with GaN (\%) & 16 & 17 & 3.4 & 0 \\
\hline $\begin{array}{c}\text { Thermal conductivity } \\
(\text { W/mm-k) }\end{array}$ & 35 & 150 & 490 & 260 \\
\hline
\end{tabular}


Sapphire substrate is fundamentally not suitable due to its very low thermal conductivity. Its ratio of performance over cost will be no longer attractive since there has been enormous progress made in GaN-on-Si technology. However, GaN-on-Si epitaxy requires transition layers to accommodate the large lattice mismatch between $\mathrm{GaN}$ and $\mathrm{Si}$ [18]. This ultimately limits the usefulness of GaN-on-Si technology for high-end power electronics, because the region of the transition layers has a very low thermal conductivity, as a result of the many interfaces, alloy nature and its poor structural quality, all of which greatly impede the heat dissipating from the GaN device down to the substrate [48]. Fortunately, all the issues just mentioned above could easily be resolved with the use of bulk GaN substrates. Besides a better thermal conductivity than $\mathrm{Si}, \mathrm{GaN}$ substrate enables homoepitaxial growth of GaN-based HEMT structures, which means no interlayer is needed so that one can expect the HEMT structure inherits the superior crystalline quality of the substrate. Despite the advantages of $\mathrm{GaN}$ substrates, they still trade off with high price and lack of large wafer size (up to 2 " to date). $\mathrm{SiC}$ substrates therefore become a good alternative, thanks to their very high thermal conductivity, low lattice mismatch with GaN, and availability of large wafer size (6" at the moment).

In this study, the growth of GaN-based HEMT structures was mainly performed on SI $\mathrm{SiC}$ substrates but also on native SI GaN substrates. The SI SiC substrates (both $4 \mathrm{H}$ and $6 \mathrm{H}$ polytypes) were supplied from Cree Inc, Norstel AB, and SiCrytal AG. And the native SI GaN substrates were supplied from Ammono S.A.

\subsubsection{Substrate pretreatment}

Prior to growth, the as-received chemical mechanical polished (CMP) surface of both $\mathrm{SiC}$ and $\mathrm{GaN}$ substrates were subject to in-situ high-temperature $\mathrm{H}_{2}$ pretreatment in the hot-wall MOCVD system for removal of surface oxides, and other contaminants. This surface cleaning process is very essential for the sequential growth. Since $\mathrm{H}_{2}$ etching mechanism is different on the surface of $\mathrm{SiC}$ and $\mathrm{GaN}$, the $\mathrm{H}_{2}$ pretreatment process needs to be deliberately optimized.

For $\mathrm{SiC}$ substrates, the surface contaminants can be completely removed by etching away a few monolayers from the $\mathrm{SiC}$ top surface. $\mathrm{The}_{2}$ etching occurs at a sufficient high temperature to dissociate the $\mathrm{SiC}$ surface, where the $\mathrm{Si}$ atoms terminated at the surface of $\mathrm{SiC}$ substrates start to evaporate and the $\mathrm{H}_{2}$ can effectively convert the surface $\mathrm{C}$ atoms to form hydrocarbons like $\mathrm{C}_{2} \mathrm{H}_{4}, \mathrm{CH}_{4}$, which then desorb from the 
surface to the gas phase [49]. A step-flow etching mode is preferred to avoid the formation of unwanted structural defects, like pits, openings, and depressions, which could adversely affects the sequential growth or lead to voids buried in the interfacial region between the substrate surface and the grown layer. To achieve the step-flow etching mode, the $\mathrm{Si}$ evaporation rate and $\mathrm{C}$ conversion rate on the top $\mathrm{SiC}$ surface have to be balanced in some way [50]. Step bunching might occur as a result of minimization of the surface energy [51]. Fig. 11 shows the typical surface morphology of (a) as-received on-axis (0001) 4H SI SiC substrates and (b) after optimizing the $\mathrm{H}_{2}$ pretreatment process to obtain 1-unit-cell-height steps.

(a)

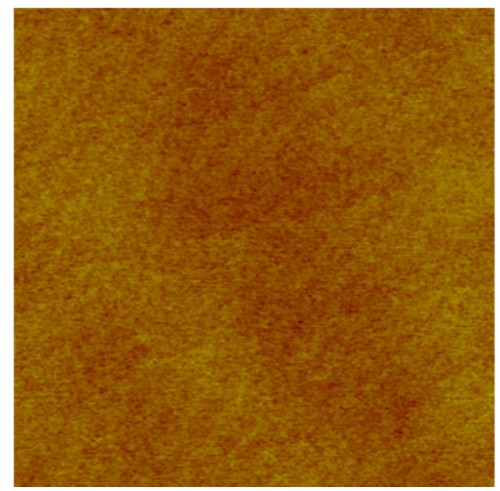

(b)

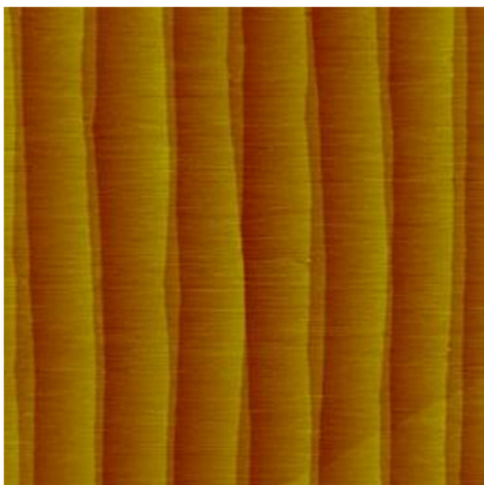

Figure 11. Atomic force microscopy (AFM) images of the surface morphologies of (a) as-received and (b) $\mathrm{H}_{2}$-treated $4 \mathrm{H} \mathrm{SI} \mathrm{SiC} \mathrm{substrates.}$

For GaN substrates, it was found that the GaN surface is vulnerable to $\mathrm{H}_{2}$ etching in the MOCVD ambient [52]. A layer-by-layer etching mode is rather difficult to achieve, likely due to large difference of the partial vapor pressure of surface $\mathrm{N}$ and $\mathrm{Ga}$ atoms [53]. Metallic Ga droplets are often seen left on the surface after $\mathrm{H}_{2}$ etching. Surface oxides and carbon contaminants are easier than residual silicon impurity to be removed. Therefore, high concentration of interfacial $\mathrm{Si}$ impurity has been one of the big issues in the GaN homoepitaxy [54]. 


\subsubsection{Growth of the AlN nucleation layer}

The main purpose to introduce an AlN nucleation layer (AIN NL) in the GaN-SiC interface is not only to accommodate the $3.5 \%$ lattice mismatch of $\mathrm{GaN}$ with $\mathrm{SiC}$ substrate, but more importantly to facilitate two-dimensional growth of the subsequent GaN epitaxial layer [55]. Typically, an AlN NL with thickness around $100 \mathrm{~nm}$ is sufficient to fulfill the purpose. Since the entire HEMT epitaxial structure is built on top of this layer, its crystalline quality has a substantial influence on the crystalline quality of the subsequent $\mathrm{GaN}$ epitaxial layer [56]. In addition, its structural parameters including crystalline quality, morphology, microstructures, and thickness play important roles for the thermal properties in the $\mathrm{GaN}-\mathrm{SiC}$ interfacial region [57]. It is evident that the joule heat transfer from the HEMT device to the substrate is impeded by so-call thermal boundary resistance (TBR) in the region of the heteroepitaxial interface due to the defective nature of the transition layers [48]. In our GaN-on-SiC growth system, the total effective TBR can be considered as a sum of a series of thermal resistances (TR) as follows,

$$
T B R_{\text {eff }}=T R_{\text {interfacial GaN }}+T R_{G a N-A l N \text { interface }}+T R_{A l N}+T R_{\text {AlN-SiC interface }} .
$$

Therefore, one can expect that improving the structural properties of the AIN NL will help reducing the $T B R_{\text {eff }}$. Since the resistance normally is directly proportional to the length, it is intuitive to reduce $T R_{A l N}$ by means of the AIN thickness reduction. However, this posts a great challenge from the growth perspective, due to the fact that in the early stage of AlN NL growth, high-density misfit dislocations are present, as a result of $1 \%$ lattice mismatch between $\mathrm{AlN}$ and $\mathrm{SiC}$, and that the low mobility of $\mathrm{Al}$ adatoms results in a slow coalescence process [58]. These structural defects certainly causes severe phonon scattering, leading to poor thermal conductivity of the AIN NL.

In this study, the growth of AlN NLs was carried out in the temperature range of 1100 ${ }^{\circ} \mathrm{C}$ to $1300{ }^{\circ} \mathrm{C}$ with the V/III ratio of $\sim 500$ to $\sim 1500$ resulting in the growth rate of $\sim 300$ to $\sim 150 \mathrm{~nm} / \mathrm{hr}$, which primarily depends on the flow rate of TMAl. As mentioned previously, the lateral growth of the AlN epilayer is largely restricted by the low mobility of $\mathrm{Al}$ adatoms. Therefore, a growth condition with high temperature is usually preferred to enhance its lateral growth to further improve crystalline quality [59]. Besides, it has been shown that surfactant-assisted growth of AlN layers enables to facilitate two-dimensional layer-by-layer or step-flow growth mode [60]. 


\subsubsection{Growth of the GaN buffer layer}

In an GaN-based HEMT epitaxial structure, the GaN buffer layer usually accounts for the most part of the growth process. Since its growth front will be the interface where the 2DEG channel is located, one can expect that the structural characteristics like surface roughness and surface morphology have a great impact on the 2DEG transport properties. In order to deliver atomically flat and continuous surface morphology, certain thickness is required for the structural development. For a GaN-on-SiC heteroepitaxial system, the thickness of 1.2 to $1.5 \mu \mathrm{m}$ is sufficient. For a GaN-on-GaN homo-epitaxial system, ideally the thickness of few hundred nano-meters should be enough, depending on the surface conditions of the GaN substrate.

The challenge for $\mathrm{GaN}$ growth on $\mathrm{SiC}$ substrates is the dislocation density reduction without deteriorating TBR. The threading dislocation (TD) density in a $\sim 2-\mu \mathrm{m}$-thick GaN layer grown on a SiC substrate is typically in the range of mid- $10^{8}$ to low- $10^{10}$ $\mathrm{cm}^{-2}$ [61]. Most of the TDs are edge- or mixed- types, the density of which is usually 1 order higher than that of the screw type in a MOCVD-grown GaN layer [62]. The issue of the high TD density in the GaN epilayer would easily be resolved by utilizing bulk GaN substrates. TD densities less than $10^{4} \mathrm{~cm}^{-2}$ in the GaN epilayer grown on a bulk GaN substrate has been successfully demonstrated [63]. However, the problems for $\mathrm{GaN}$ growth on $\mathrm{GaN}$ substrates are the high interfacial $\mathrm{Si}, \mathrm{C}, \mathrm{O}$ impurities [50] and large-scale three-dimensional surface morphology [64]. Both of them could be attributed to the lower thermal stability of $\mathrm{GaN}$ surface compared to that of $\mathrm{SiC}$ surface so that no effective in-situ substrate surface pretreatment has been developed yet.

In addition to the structural requirements, the $\mathrm{GaN}$ buffer layer has to be electrically semi-insulating to prevent a parallel conduction in a HEMT device. Such an electrical property can be achieved by doping the $\mathrm{GaN}$ with acceptor-like impurities. The mechanism will be elucidated later. On the other hand, the concentrations of these acceptor-like impurities shall be minimized in the proximity of the 2DEG channel to alleviate the trapping effect, which degrade 2DEG properties [65], and would later cause current collapse at the device level [66][67]. Therefore, the doping profile needs to be optimized to obtain a highly resistive and trap-free GaN layer. To distinguish such a GaN layer containing two very different properties, the bottom thick semiinsulating layer is commonly called GaN buffer layer and the top thin intrinsic layer is called GaN spacer layer.

The acceptor-like impurities typically used are carbon or iron. Which one is the best to increase the resistivity of the GaN buffer layer is still under debate [68]. Nevertheless, 
both doping processes have pros and cons from the growth point of view. The merit of the Fe-doping is the incorporation of $\mathrm{Fe}$ into $\mathrm{GaN}$ from its precursor (ferrocene) being rather growth-condition independent [69], so that the doping process window is relatively large which makes it feasible to establish a stable and reproducible growth process. However, the trade-off of the Fe-doping is that the incorporation of Fe would not stop immediately after switching off the doping gas from the growth zone; until all of the Fe adatoms riding on the growth surface front are consumed the incorporation into the GaN layer will gradually decrease [70]. This surfactant-related memory effect renders the doping difficult to control, which limits the profile optimization. In contrast to the Fe doping, carbon doping can be implemented with the residual carbon cracked from the metal-organic precursor, TMGa $\left(\mathrm{Ga}\left(\mathrm{CH}_{3}\right)_{3}\right)$, during the $\mathrm{GaN}$ growth [71]. Hence, at a given growth condition, the rate of carbon incorporation is linearly proportional to the TMGa flow [72]. Moreover, the carbon incorporation is thus largely dependent on the growth parameters such as temperature, pressure, $\mathrm{NH}_{3}$ flow and so forth. In general, the way to reduce the carbon incorporation is to facilitate the conversion of the residual hydrocarbon to the stable $\mathrm{CH}_{4}$ or other forms, which can be achieved by increasing the growth temperature, pressure, $\mathrm{NH}_{3}$ flow [72]. With this growth-condition-tuned doping scheme, a very abrupt transition can be readily obtained. However, each growth parameter needs to be carefully calibrated over some time, in order to have a precise control for the carbon incorporation.

Since the residual carbon was used to make GaN buffer layers semi-insulating for this entire work, here some more attention is paid to the mechanism. Despite that intensive experimental and theoretical studies have been made over the past two decades, the role of carbon in GaN remains an unsettled issue. The early results indicated that formation of interstitial carbon is unlikely due to its high formation energy and that the substitutional carbon in $\mathrm{GaN}$ is amphoteric. The amphoteric property means that carbon is a donor-like impurity when it is incorporated on the Ga site and it behaves as an acceptor-like impurity while sitting on the $\mathrm{N}$ site. The calculated energy levels for the $\mathrm{C}_{\mathrm{Ga}}$ and the $\mathrm{C}_{\mathrm{N}}$ are $0.2 \mathrm{eV}$ below the conduction band minimum and $0.3 \mathrm{eV}$ above the valance band maximum, respectively [73][74]. The type of site occupied by carbon atoms depends on the growth condition and Fermi level [75]. Under N-rich growth condition, which is believed as the most common condition in MOCVD, the GaN becomes semi-insulating with the Fermi level pinned near middle of the bandgap as a result of a self-compensation by roughly equal numbers of $\mathrm{C}_{\mathrm{Ga}}$ and $\mathrm{C}_{\mathrm{N}}$ incorporations. This self-compensation mechanism also explained why p-type GaN cannot be realized by carbon doping, even though the $\mathrm{C}_{\mathrm{N}}$ has a shallow acceptor level. However, lately, a result based on a new calculation method shows $\mathrm{C}_{\mathrm{N}}$ is not a shallow acceptor but a very deep acceptor with an energy level of 0.9 above the valance band maximum, 
pinning the Fermi level in its vicinity thus obtaining the semi-insulating property [76][77].

In this study, the growth of $\mathrm{C}$-doped $\mathrm{GaN}$ buffer and spacer layers was carried out in the temperature range of $980{ }^{\circ} \mathrm{C}$ to $1080{ }^{\circ} \mathrm{C}$, at the pressure range of 25 to $100 \mathrm{mbar}$, with the V/III ratio of $\sim 500$ to $\sim 1500$, in a mixture of $\mathrm{N}_{2}$ and $\mathrm{H}_{2}$ carrier gases, resulting in the growth rate of $0.4 \mu \mathrm{m} / \mathrm{hr}$ to $1.6 \mu \mathrm{m} / \mathrm{hr}$. The growth conditions were adjusted to meet the carbon profile specified.

\subsubsection{Growth of the HEMT active layers}

The thin, but the most decisive layer in the HEMT structure: the barrier layer. There are several different types of barrier layers used in GaN-based HEMT structures, including an ultra-thin AlN layer [11], ternary alloys like $\mathrm{Al}_{x} \mathrm{Ga}_{1-\mathrm{x}} \mathrm{N}$ [23], $\mathrm{In}_{\mathrm{x}} \mathrm{Al}_{1-\mathrm{x}} \mathrm{N}$ [78], or the quaternary alloy $\operatorname{In}_{x} \mathrm{Al}_{y} \mathrm{Ga}_{1-\mathrm{x}-\mathrm{y}} \mathrm{N}$ [79]. In this work, the ternary alloys were the main focus for the barrier growth development. The thickness and the composition of the barrier layer determine the 2DEG density, as explained in the Chapter 2. Therefore, the structural parameters of a barrier layer need to be controlled with high precision to meet the $2 \mathrm{DEG}$ properties specified. Before going into the details of the major types of barrier layers, it is worth to mention the other important layer, which is often inserted between the GaN spacer and the barrier layer: 1-nm-thick AlN exclusion layer $\left(A I N_{e x}\right)$. The $\mathrm{AlN}_{\mathrm{ex}}$ layer is used to exclude the $2 \mathrm{DEG}$ electron wavefunction from penetrating into the barrier alloy that causes alloy scattering decreasing the 2DEG mobility [27][28]. With the $\mathrm{AlN}_{\mathrm{ex}}$ layer, the room-temperature 2DEG mobility can be improved to above $2000 \mathrm{~cm}^{2} / \mathrm{V}$-s [29].

\section{AlGaN barrier layer}

This is the most common barrier layer used in GaN-based HEMT structures. The typical thickness and composition of Al content are 15 to $30 \mathrm{~nm}$ and 15 to $30 \%$, respectively, which give rise to a 2 DEG density ranging from $2.2 \times 10^{12}$ to $1.0 \times 10^{13} \mathrm{~cm}^{-}$ ${ }^{2}$, and the mobility below $1600 \mathrm{~cm}^{2} / \mathrm{V}$-s. In this study, the growth of AlGaN barrier layers was carried out right after the growth of GaN spacer layers, so that its growth condition is the same as that of the $\mathrm{GaN}$ spacer layer. The $\mathrm{Al}$ content was controlled with reference to the gas phase ratio of TMAl over TMAl plus TMGa. It should be noted that high $\mathrm{Al}$ content might lead to a local relaxation that reduces 2DEG density and mobility or a plastic strain relaxation in the form of cracks. 


\section{InAlN barrier layer}

One of the great advantages using InAlN as the barrier layer is that it offers very high spontaneous polarization to induce 2 to 3 time higher 2DEG density than $\mathrm{AlGaN}$ under a strain-free condition when an $\operatorname{In}_{0.18} \mathrm{Al}_{0.82} \mathrm{~N}$ layer is grown [78]. This may considerably improve the thermal stability of a HEMT device operating at high temperature [80]. Furthermore, thanks to its high spontaneous polarization, a thinner barrier structure with a thickness below $15 \mathrm{~nm}$ is permitted, which allows fabrication of a shorter current channel to increase the device operating frequency without encountering the short-channel effects [81]. However, a high-structural-quality InAlN layer is difficult to grow due to the large immiscibility and the large difference of the thermal stability between $\mathrm{InN}$ and AlN. A grainy-like morphology with pits is commonly seen for a thin InAlN layer. This is also the reason very low 2DEG mobility $<300 \mathrm{~cm}^{2} / \mathrm{V}$-s is usually obtained in the InAlN/GaN heterostructure. Thus, the $\mathrm{AlN}_{\mathrm{ex}}$ layer must be used in this case to sustain the mobility above $1000 \mathrm{~cm}^{2} / \mathrm{V}$-s [82][83]. In this study, the growth of InAIN barrier layers was carried out in a low temperature regime between 700 to $800{ }^{\circ} \mathrm{C}$, at a pressure of 50 mbar with $\mathrm{N}_{2}$ as the carrier gas, to increase the indium corporation in the InAlN layer. The In content was mostly determined by the growth temperature.

Fig. 12 shows the typical AFM images of the surface morphologies of InAlN/GaN and AlGaN HEMT structures.

(a)

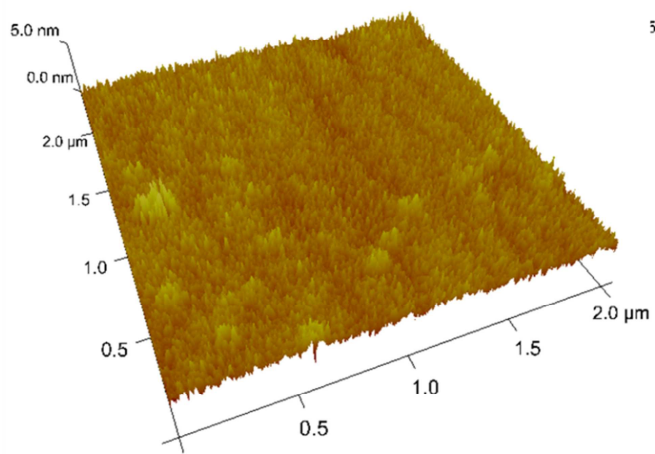

(b)

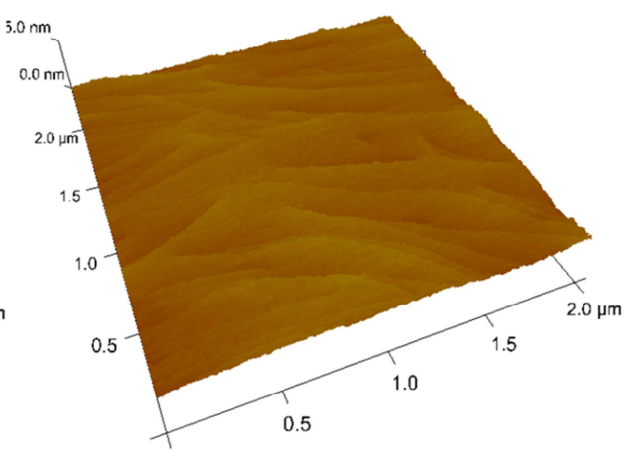

Figure 12. AFM images of the surface morphologies of (a) an InAIN/GaN HEMT structures and (b) an AlGaN/GaN HEMT structures. 


\subsubsection{Surface passivation}

It was found that the surface states, charges, and traps created by dangling bonds, vacancies, threading dislocations accessible at the surface, and ion absorbed could be reduced, filled, or neutralized by means of surface passivation [84]. Since the 2DEG density is associated with the defect states at the near surface of the HEMT structures, and is also highly dependent on the piezoelectric polarization, as explained earlier in Chapter 2, it is important to have control over these near-surface properties to improve the reliability of the HEMT device performance. Bruce M. Green et al. first demonstrated that silicon nitride grown by plasma-enhanced CVD for surface passivation of an $\mathrm{AlGaN} / \mathrm{GaN}$ HEMT structure largely increased the power density and the breakdown voltage. Later, an in-situ $\mathrm{Si}_{3} \mathrm{~N}_{4}$ deposition was developed in the MOCVD process for AlGaN/GaN HEMTs [85]. In addition to the surface passivation, it was shown that the $\mathrm{Si}_{3} \mathrm{~N}_{4}$ layer not only can supply additional biaxial strain to AlGaN leading to higher 2DEG density, but also enables to prevent the strain relaxation of the $\mathrm{AlGaN}$ barrier layer operating at high temperature [86]. This is particularly essential when a high-Al-content AlGaN or a pure AlN barrier is applied in the HEMT structure.

Some improvements of AlGaN/GaN HEMTs in device performance, reliability and reproducibility were also seen in the HEMT epitaxial structures capped by a thin GaN layer [87]. Ponky Ivo et al. reported that the robustness of AlGaN/GaN HEMTs under high DC stress was significantly improved by adding a thin GaN cap [88]. They attributed the improvement to the GaN cap, which shields the AlGaN layer in the vicinity of the gate by a factor of two reduced electrical field compared with the one without the GaN cap, consequently minimizing a local relaxation of the AlGaN. Another benefit from the GaN cap layer is to achieve controlled surface properties since an $\mathrm{Al}$ accumulation was observed at the surface due to a preferential etching of Ga out of AlGaN during the cooling process in a MOVPE reactor [89].

In this study, some of the HEMT structures were grown with a 3-nm-thick GaN cap layer. The growth of the thin GaN cap was carried out right after the barrier layer growth, so that its growth condition is the same as that of the barrier layer. The V/III ratio for the GaN cap is between 600 to 1300 , which results in growth rate from 5 to $15 \mathrm{~nm} / \mathrm{min}$. Most importantly, it should be noticed that the thickness of the GaN cap would be reduced by an unintentional thermal/chemical etching process during the cooling procedure [89]. The etched thickness in our reactor is between 3 to $15 \mathrm{~nm}$, largely depending on the cooling conditions. 


\section{5}

\section{Characterizations of GaN-based HEMT structures}

\subsection{Optical microscopy}

Optical microscopy (OM) is an easy technique to provide a fast and large-area surface topography for samples.

Since SiC substrates and nitride epitaxial layers are transparent, Nomarsky differential interference contrast (NDIC) is often used to enhance the contrast along the lines and edges of the morphological features making structural defects more visible in observation. The mechanism of the NDIC is to produce interference as a result of recombination of two orthogonally polarized beams having gone through structural features that lead to a different optical path.

Some growth-temperature-related structural features in $\mathrm{GaN}$ layers can be easily observed in the optical microscope. Fig. 13 shows the optical images of the GaN layers grown at varied temperatures. For the GaN growth at 1050 and $1080{ }^{\circ} \mathrm{C}$, plain and featureless morphology was observed, indicating that the surface is flat and continuous. However, one can see dot-like and trench-like defects appearing in the GaN layers 
grown at $1000{ }^{\circ} \mathrm{C}$ and $1100{ }^{\circ} \mathrm{C}$, respectively. These morphological features observed by optical microscope help to define a suitable temperature regime for growth of $\mathrm{GaN}$ epilayers, and also serve as the signatures of the growth process, which is particularly useful when the process drift takes place due to aging of the isolation and the susceptor.
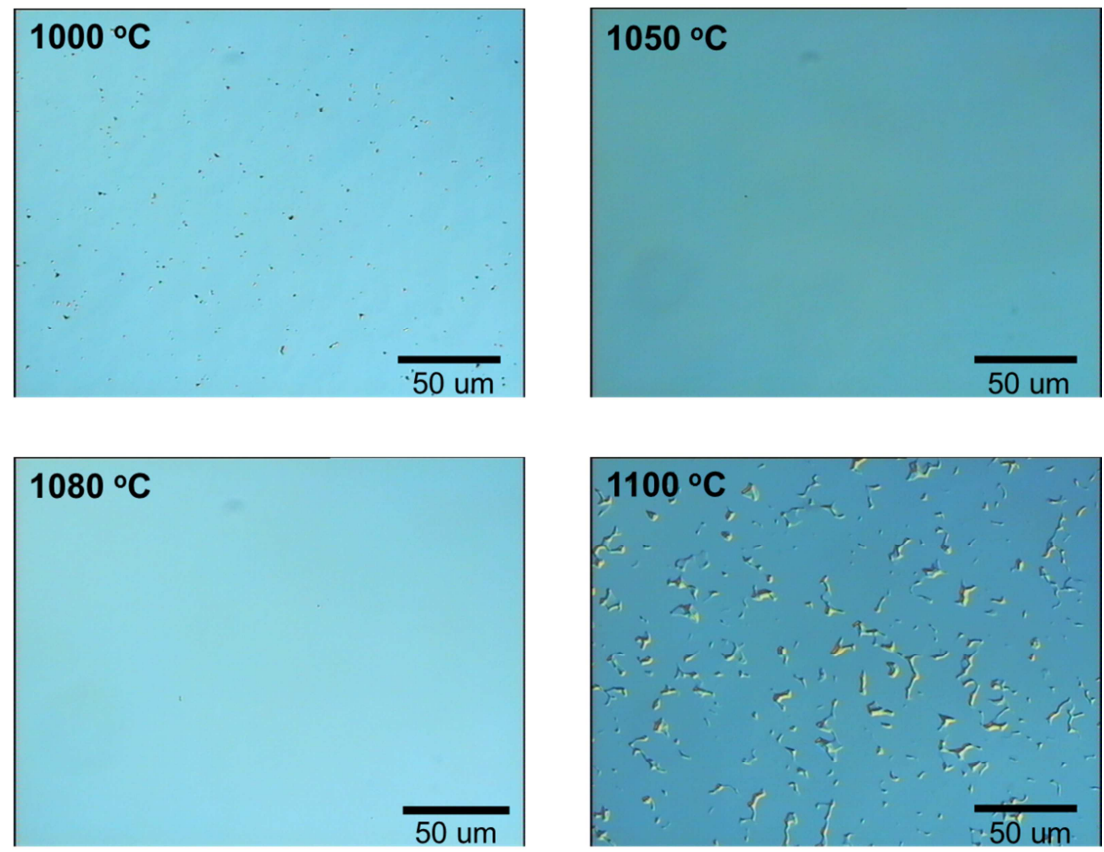

Figure 13. OM images of surface morphologies of the GaN epilayers grown at various temperatures. 


\subsection{Spectral interferometry}

A white-light spectral interferometer was utilized to extract a total thickness of IIInitride epilayers grown on $\mathrm{SiC}$ substrates.

The principal is based on analyzing the interference spectrum composed of reflected lights, which contains the film thickness information. A white light from a LED with wavelength in 410 to $710 \mathrm{~nm}$ is directed to the surface of the sample at normal incidence through a fiber. The reflected lights from the surface and the interface with $\mathrm{SiC}$ substrate are collected by the fiber and sent to a monochromator. Since these two reflected lights have a phase difference due to different optical path length, approximately the twice of the total epilayer thickness multiplied by the major layer refractive index, the total epilayer thickness can be extracted from a fringe analysis of the interference spectrum.

The differentiable variation in thickness can be down to $10 \mathrm{~nm}$. The beam size of the white light is $0.5 \mathrm{~mm}$ spot, enabling high-resolution thickness mapping over an entire epiwafer. Fig. 14 shows a typical thickness map of a GaN HEMT structure grown on a $100 \mathrm{~mm} \mathrm{SiC}$ wafer. The thickness spread (standard deviation / mean) is also calculated.
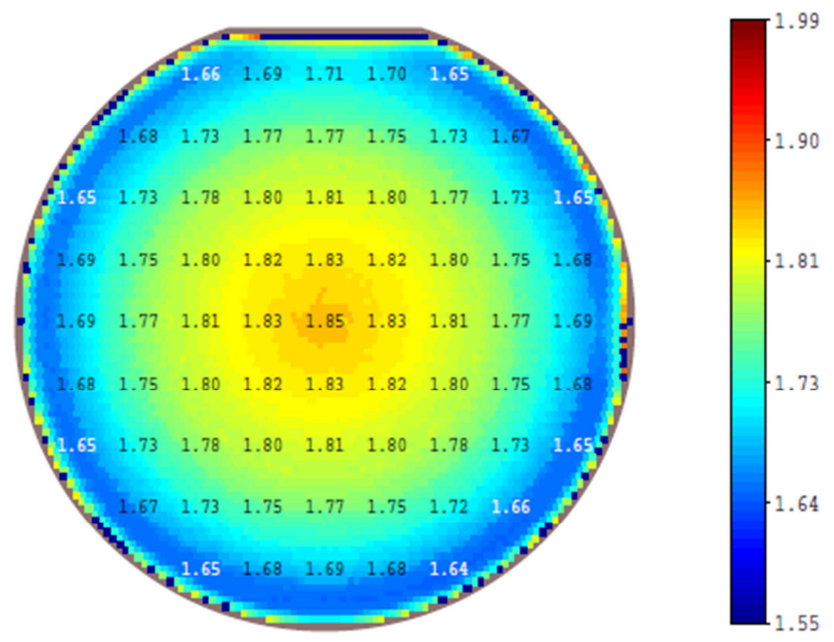

Figure 14. An example of a thickness map over a 100-mm AlGaN/GaN HEMT epiwafer.

Mean thickness $=1.74 \mu \mathrm{m}$

Max thickness $=1.90 \mu \mathrm{m}$

Min thickness $=1.64 \mu \mathrm{m}$

Standard deviation (sigma) $=.059 \mu \mathrm{m}$

sigma $/$ mean $=3.48$

$(\max -\min ) /$ mean $=14.5 \%$

7392 of total 7477 points used. 


\subsection{Contactless electrical measurements}

Contactless electrical measurement techniques possess many advantages over the conventional four-point probe Hall measurement to analyze the electrical properties of semiconductor materials. "Contactless" means no post-processing for contact formation is needed so that it is non-destructive and enables to perform measurement mapping over an entire epiwafer. Most importantly, it offers fast feedback to the growth. The only requirement to perform the contactless electrical measurements on HEMT samples is that semi-insulating (highly-resistive) substrates have to be used to avoid the disturbance from the additional free carriers contributed from the substrate. We noticed that the contactless measurements are sometimes more sensitive to the ambience, like temperature, humidity and lighting conditions. Nevertheless, in general, the results obtained by the contactless techniques in this study were in good agreement with the ones determined by four-point probe Hall measurements performed by our collaboration partners in Chalmers University of Technology.

Two contactless techniques were used to measure the electrical properties of HEMT structures.

\section{Sheet resistance measurement}

To determine the sheet resistance (Rs) of HEMT structures, an eddy-current-based commercial setup (Eichhorn Hausmann MX604) was employed. This technique depends on a feedback system monitoring the power absorbed in the measured sample. The measurement starts with ratio-frequency alternating current flowing through coils that circulate a ferrite core, which then induces an oscillating magnetic flied at the probing area near the sample. The sample is thus electromagnetically coupled leading to power absorption and creation of eddy current. The relationship between the power absorbed $P$ in this process and the $R_{S}$ can be expressed as follows [90]:

$$
P=\left(\frac{E_{T}^{2}}{8 \pi n^{2}}\right) \sigma t=\left(\frac{E_{T}^{2}}{8 \pi n^{2}}\right) \frac{1}{\rho} t=\left(\frac{E_{T}^{2}}{8 \pi n^{2}}\right) \frac{1}{R_{S}},
$$

where $E_{T}$ is rms primary RF voltage, $n$ is number of primary turns on the core, $\sigma$ is semiconductor conductivity, $\rho$ is semiconductor resistivity and t is semiconductor thickness.

Therefore, $R_{S}$ can be extracted.

The system has a working range from 50 to $3000 \mathrm{ohm} / \mathrm{square}$. Prior to measurement, the system is referenced with a silicon wafer certificated with $R_{S}$ of $398.7 \mathrm{ohm} / \mathrm{square}$ at room temperature. It should be noted that continuous measurements might result in 
a temporary $R_{S}$ drift-up phenomenon due to Joule heating of the measured sample by the eddy current.

\section{Sheet carrier density and mobility measurement}

To measure sheet carrier density and mobility, a microwave-based commercial system (Lehighton 1610E100M) was used. The measurement begins with initializing a10 GHz microwave and directing it to the sample surface, which is also perpendicularly subject to a series of magnetic fields from 0 to $10 \mathrm{kG}$. The system records the forward, reflected, and Hall power signals at each forward and reverse magnetic field, and converts them into reflection coefficients, which are then used to calculate the conductivity tensors $\sigma_{X X}, \sigma_{X Y}$ Once the field-dependent conductivity tensors $\sigma_{X X}(H)$, $\sigma_{X Y}(H)$ are obtained, all other important parameters like Hall coefficient $R_{H}$, resistivity $\rho$, mobility $\mu$ and sheet carrier density $N_{S}$ in a single-carrier model can be determined as follows [91]:

$$
\begin{gathered}
R_{H}=-\frac{1}{H} \times \frac{\sigma_{X X}(H)}{\sigma_{X X}^{2}(H)+\sigma_{X Y}^{2}(H)}, \\
\rho(H)=\frac{\sigma_{X X}(H)}{\sigma_{X X}^{2}(H)+\sigma_{X Y}^{2}(H)}, \\
\mu=\frac{-R_{H}}{\rho(H)} \\
N_{S}=\frac{-1}{e R_{H}}
\end{gathered}
$$

Provided a multi-carrier model is chosen, the sum of the conductivity tensors for each layer will be considered. The system thus can generate a mobility spectrum where multi-carrier density and mobility are presented, based on calculations taking all fielddependent measurements into account and fitted with an algorithm.

It is recommended to input the epilayer thickness and the $R_{S}$ in order to increase the accuracy of data acquisition. Therefore, only carrier density and mobility are determined in the measurement. 


\subsection{Mercury-probe capacitance-voltage measurement}

The mercury-probe capacitance-voltage (CV) measurement offers a rapid and nondestructive testing to obtain the electrical properties of HEMT structures.

A double circular $\mathrm{Hg}$ contact probe $\mathrm{CV}$ setup is used for the measurement. When the $\mathrm{Hg}$ is put in contact with the surface of the samples, two Schottky contacts of diameters $3 \mathrm{~mm}$ and $0.7 \mathrm{~mm}$ are formed. The larger contact is set up in forward bias so that this Schottky contact can be considered as a quasi-ohmic contact relatively to the smaller contact. This means it is assumed that the applied voltage is entirely dropped across the smaller Schottky contact, which is placed in reverse bias. Thus, this technique mainly depends on measuring the depletion capacitance $(C)$ of the smaller Schottky contact versus applied reverse bias $V_{R}$ plus a sinusoidal ac voltage $\boldsymbol{v}(100 \mathrm{mV})$ operating at high frequency $(100 \mathrm{~Hz}$ to $1 \mathrm{MHz})$.

Provided an external voltage $V_{R}$ plus a small ac voltage $\mathrm{d} \boldsymbol{v}$ is applied to the metalsemiconductor contact (Hg-HEMT), the $\mathrm{d} \boldsymbol{v}$ will induce increment charges on the both sides of the reverse-biased junction, namely $d Q_{m}$ (charges in the metal) and $d Q_{s}$ (space charges in the semiconductor).

$$
\begin{gathered}
d Q_{m}=-d Q_{s}, \\
Q_{s}=q A \int_{0}^{d} N_{D}^{+} d x \\
C=\frac{d Q_{m}}{d v}=-\frac{d Q_{s}}{d v}=-\frac{d\left[q A \int_{0}^{d} N_{D}^{+} d x\right]}{d v}=-q A \frac{d\left[N_{D}^{+}(x) d\right]}{d v},
\end{gathered}
$$

where $A$ is the contact area, $d$ is the depletion depth and $N_{D}^{+}$is the ionized donor density.

The characteristics of the depletion region of the Schottky contact can be simplified as a parallel plate capacitor. ( $K_{s}$ is the semiconductor dielectric constant.)

$$
\begin{gathered}
C=\frac{K_{S} \varepsilon_{0} A}{d}, \\
\frac{d \boldsymbol{d}}{d v}=-\frac{K_{S} \varepsilon_{0} A d C}{C^{2} d v},
\end{gathered}
$$


The free carrier distribution in the semiconductor, $n_{s}(\mathrm{x})$, can be derived from Eq. 22:

$$
\begin{gathered}
n_{S}(x)=-N_{D}^{+}(x)=\frac{C}{q A} \frac{d v}{d \boldsymbol{d}}=\frac{C}{q A}\left(-\frac{C^{2} d v}{K_{S} \varepsilon_{0} A d C}\right), \\
=-\frac{C^{3}}{q K_{S} \varepsilon_{0} A^{2}}\left(\frac{d C}{d v}\right)^{-1},
\end{gathered}
$$

A typical $n_{s}$ distribution in an AlGaN/GaN HEMT structure is shown in Fig. 15(a). The $n_{s}$ are rapidly reduced from the $\mathrm{AlGaN} / \mathrm{GaN}$ interface down to the substrate, indicating there is no free carrier in the GaN buffer layer.

On the other hand, by integrating the area under the volume concentration curve, the sheet carrier density, $N_{s}$ (2DEG density), can be obtained as below and plotted like Fig. $15(\mathrm{~b})$.

$$
N_{s}=\int_{0}^{V_{R}} n_{s}(x) d V,
$$

As shown in Fig. 15(b), when the reverse bias $V_{R}$ is increased, this expands the depletion region through the $2 \mathrm{DEG}$ so that the integrated sheet carrier density increases. The increase of the integrated sheet carrier density stops at a point $V_{p}$ where all free carriers are depleted. The $V_{p}$ is called pinch-off voltage of the HEMT structure. Besides, the thickness of the AlGaN barrier, $t$, can be estimated through a simplified model assuming a parallel plate capacitor that,

$$
\begin{gathered}
C=\frac{\Delta n_{s}}{\Delta V}=\varepsilon \varepsilon_{o} \frac{A}{t}, \\
t=\varepsilon \varepsilon_{o} A\left(\frac{\Delta V}{\Delta n_{s}}\right),
\end{gathered}
$$


It should be noted that some small errors of the contact area $A$ might be introduced to the measurement as a result of the imprecise $\mathrm{Hg}$ contact size. And, continuous measuring on the same spot of the sample might cause a temporary 2DEG reduction since the free carriers are pushed into deep traps in the $\mathrm{GaN}$ buffer layer.

(a)

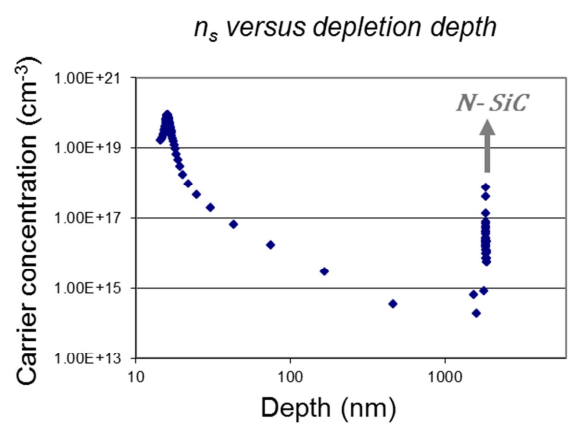

(b)

Sheet carrier density versus bias

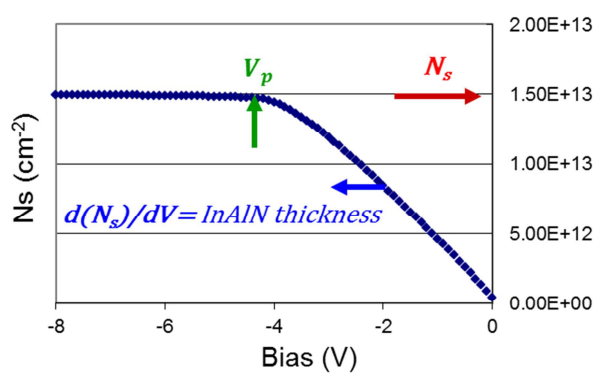

Figure 15. (a) A plot of $n_{s}$ versus depletion depth. (b) A plot of $N_{s}$ versus depletion bias.

\subsection{Atomic force microscopy}

Atomic force microscopy (AFM) is one common technique among the branch of scanning probe microscopy used for imaging high-resolution nanometer-scale surface topography. It is non-destructive and can be operated in atmosphere. Hence, combining it with optical microscopy, the morphological features scaling from few angstroms to hundred micrometers can be imaged and presented.

The AFM is based on a feedback system detecting the probe deflection due to the interaction force between the probe and the sample surface, and then translating the deflection signals collected from each scan over the surface into a topological image. The measurement starts by bringing a sharp tip on a cantilever to the proximity of the sample surface. The probing depends on different interaction forces between the tip and the surface atoms that cause the cantilever to deflect, including mechanical contact force, Van der Waals forces, electrostatic forces and so forth. The displacement of a laser beam reflected off the backside of the cantilever is detected by two closely spaced position-sensitive photodiodes to monitor the deflection. In order to position 
and scan the probe precisely along $\mathrm{x}-\mathrm{y}$ - $\mathrm{z}$ - directions over the sample surface, the cantilever and the photo detection system are attached to a piezoelectric scanner, the movement of which is controlled by an applied voltage.

AFM can be operated in three major different modes. A summary of the instrumental features of each mode is listed in the Table IV.

Table IV. Features of AFM at different operation modes

\begin{tabular}{|c|c|c|c|}
\hline Operation mode & Contact & Non-contact & Tapping \\
\hline $\begin{array}{c}\text { Spatial resolution } \\
\text { Tip-sample damage } \\
\text { risk }\end{array}$ & High & Low & Low \\
\hline $\begin{array}{c}\text { Contact type } \\
\text { Interaction forces }\end{array}$ & Physic contact \\
\hline Short-range & No & No contact & Touch for a short time \\
\hline $\begin{array}{c}\text { Detected signals } \\
\text { Cantilever oscillation } \\
\text { amplitude }\end{array}$ & Cantilever deflection & $\begin{array}{r}\text { Lantilever oscillation } \\
\text { amplitude }\end{array}$ & $\begin{array}{c}\text { Cantilever oscillation } \\
\text { amplitude }\end{array}$ \\
\hline
\end{tabular}

As indicated in the table, the tapping mode AFM possesses the advantages of both contact mode and non-contact mode AFM; namely, the high spatial resolution and the low risk of tip-sample damage. Thus, the AFM measurements were performed at tapping mode in this study.

To measure the surface morphology of SiC substrates, III-nitride epilayers, and HEMT structures, an AFM system (Vecco Dimension 3100) was employed. The system permits the spatial resolution $0.3 \sim 1 \AA$ along the vertical direction and $1 \sim 5 \mathrm{~nm}$ along the lateral direction, the resolutions of which are limited by the system background noise and the tip radius of curvature of $5 \sim 10 \mathrm{~nm}$ used in this study, respectively. 


\subsection{High-resolution x-ray diffractometry}

High-resolution x-ray diffractometry (HR-XRD) has been widely exploited to characterize the structural properties of III-nitride materials, such as determination of the lattice constants, the thickness, and the alloy composition, and evaluation of the crystalline quality and the strain status. It is non-destructive and capable of rapid turnaround characterization cycles for samples and mapping over large epi-wafers.

Since the dimension of the x-ray wavelength is in the same order of the lattice spacing of the material, the periodic arrays of atoms in the material thus serve as a diffraction grating giving rise to a diffraction pattern as a result of interference superposed of the $\mathrm{x}$-rays scattered from the sample. This is the fundamental $\mathrm{x}$-ray crystallography. The $\mathrm{XRD}$ measurement starts with $\mathrm{x}$-ray generation in an $\mathrm{x}$-ray tube by high-energy electron bombardment on a metal target (usually copper) to obtain the characteristic spectrum due to electron de-excitation of the metal atoms. The x-rays are then filtered by a monochromator to be a single-wavelength beam before impinging on the studied sample. When the $\mathrm{x}$-ray beam is incident to the sample, the $\mathrm{x}$-ray is elastically scattered by the core electrons of the lattice atoms and reflected to a detector. Constructive interference from the $\mathrm{x}$-ray beam reflected off a set of lattice planes occurs as the Bragg's law is fulfilled:

$$
n \lambda=2 d \sin \theta,
$$

where $n$ is the order of the diffraction, $\lambda$ is the wavelength of the incident X-ray beam, $d$ is the interplanar spacing of lattice planes, and $\theta$ is the incident angle.

The Eq. 26 can be re-written as the Eq. 27, when the interplanar spacing $d$ is specified as one between two adjacent planes $(h k l)$, denoted as $d_{h k l}$.

$$
\frac{d}{n}=d_{h k l}=\frac{\lambda}{2 \sin \theta},
$$

Considering the wurtzite hexagonal crystal structure of the epitaxial III-nitride materials, the interplanar spacing of the $\{h k l\}$ planes, is given by [83]:

$$
d_{h k l}=\left(\sqrt{\frac{4}{3}\left(\frac{h^{2}+h k+k^{2}}{a^{2}}\right)+\frac{l^{2}}{c^{2}}}\right)^{-1},
$$

where a, $\mathrm{c}$ are the lattice constants. 
It should be noted that it is common to use four Miller indices, $\{h k i l\}$, where $i=$ $(h+k)$, to describe lattice planes in the hexagonal structure, which helps to classify

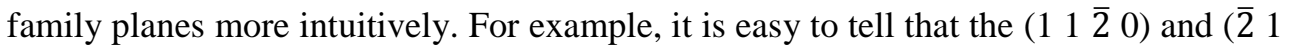
$10)$ planes are in the same set of family planes, but it would be difficult when they are presented with only three Miller indices, as ( $\left.\begin{array}{lll}1 & 1 & 0\end{array}\right)$ and ( $\left(\begin{array}{lll}2 & 1 & 0\end{array}\right)$ planes.

For this study, a high-resolution x-ray diffractometer (Philips X'Pert MRD) with $\lambda=$ $0.15406 \mathrm{~nm}$ of $\mathrm{Cu} \mathrm{K}_{a 1}$ radiation was employed. The HR-XRD system is equipped with a hybrid mirror and a triple-axis crystal as the primary and secondary optics, respectively, in which a resolution of $\sim 0.003^{\circ}(\sim 11 \operatorname{arcsec})$ can be achieved.

Three different modes of HR-XRD measurements were performed to access the structural parameters of HEMT structures.

\section{Symmetric $2 \theta-\omega$ scan:}

Symmetric $2 \theta-\omega$ scan of the (0002) reflections for the III-nitride epitaxial layers in HEMT structures were used to extract the composition of the AlGaN barrier layer and thickness of the AlN nucleation layer, the AlGaN barrier layer and the thin GaN cap layer.

For the composition, owing to the fact that the thin AlGaN layer is psudomorphically grown on the GaN layer, $a$ lattice constant of the AlGaN is fully strained to the underlying GaN, which means: $a^{\text {AlGaN }}=a_{o}^{G a N}$.

In this case, with consideration of the unit cell deformation the $\mathrm{Al}$ content $x$ in $\mathrm{Al}_{\mathrm{x}} \mathrm{Ga}_{1}$ ${ }_{x} \mathrm{~N}$ can be determined [92]:

$$
x=-\frac{a^{A l G a N} c^{A l G a N}(1+v)-a^{A l G a N} c_{o}^{G a N}-a_{o}^{G a N} c^{A l G a N} v}{a^{A l G a N}\left(c_{o}^{G a N}-c_{o}^{A l N}\right)+c^{A l G a N} v\left(a_{o}^{G a N}-a_{o}^{A l N}\right)},
$$

where $c_{o}^{G a N}, a_{o}^{G a N}, c_{o}^{A l N}, a_{o}^{A l N}$ are the strain-free lattice constants of GaN, and AlN. $v$ is Poisson's ratio, the value of which is 0.2 is in this study [93].

Therefore, $c^{\text {AlGaN }}$ is the only one variable in the Eq. 29, which can be calculated from the peak position of the $(00 l)$ reflection in the symmetric $2 \theta-\omega$ scan. 
For the thicknesses, when the epilayers are flat, the interference fringes produced from each layer due to different optical paths of the x-ray can be observed in the $2 \theta-\omega$ spectrum. Thus, the thickness, $T$, can be calculated by [94]:

$$
T=\frac{\lambda\left(n_{1}-n_{2}\right)}{2\left(\sin 2 \theta_{1}-\sin 2 \theta_{2}\right)},
$$

where $\lambda$ is the wavelength of the X-ray, $n_{1}, n_{2}$ are the first and second orders of fringes, and the corresponding angles of which are $2 \theta_{1}, 2 \theta_{2}$, respectively.

The determination of the structural parameters mentioned above was done by using simulation software (PANalytical X's Epitaxy) to fit the peaks and the interference fringes in the measured spectrum.

\section{2. $\omega$ scan (rocking curves):}

$\omega$ scans of on-axis (0002) reflections in symmetric diffraction geometry, and off-axis $(10 \overline{1} 2)$ or $(10 \overline{1} 5)$ reflections in skew symmetric diffraction geometry for the GaN buffer layer and the AlN nucleation layer in HEMT structures were used to evaluate the crystalline quality of each epilayer.

In heteroepitaxy epitaxial layers usually contain very high density of threading dislocations due to large lattice mismatch with foreign substrates. The characteristics of threading dislocations are commonly described by a line direction, which indicates the direction of the dislocation propagation, and the Burgers vector $\boldsymbol{b}$, which presents the direction and magnitude of distortion to the crystal lattice. In [0001]-oriented epilayers, threading dislocations propagating along [0001] can be divided into the edge type with $\boldsymbol{b}=1 / 3\langle 11 \overline{2} 0\rangle$, the screw type with $\boldsymbol{b}=\langle 0001\rangle$, and the mixed type with $\boldsymbol{b}=1 / 3\langle 11 \overline{2} 3\rangle[95][96]$. As deduced by the Burgers vectors, when screw or mixed dislocations are present in the epilayer, the crystal lattices are distorted over the $(00 l)$ planes. Thus, $\omega$ scans of $(00 l)$ reflections can be used to measure the broadening of the rocking curve as a result of lattice tilt. And when the edge and mixed dislocations are present, the crystal lattices are distorted over the $(h k l)$ planes with $h$ or $k$ nonzero. In this case, $\omega$ scans of off-axis $(h k l)$ reflections in skew symmetric diffraction geometry are often used to measure the broadening of the rocking curve associated with these inplane distortions, lattice twist. Therefore, in this study, the peak width of rocking curves of (002), (102) and (105) reflections are used as a crystalline quality indicator. 


\section{Reciprocal space mapping:}

This scan mode was performed in asymmetric geometry along the (105) reflections of the III-nitride epitaxial layers in HEMT structures to access the condition of biaxial strain and relaxation of the thin epitaxial layers, like AlGaN or InAlN barrier, and AlN nucleation layer.

A reciprocal space map is constructed by the reflected spectrums obtained from $2 \theta-\omega$ scans at successively varied $\omega$. The strain, relaxation, crystalline quality, and other structural parameters of an epilayer can be visualized in the map by the shape and distribution analysis of the diffraction intensity contours [97]. 


\subsection{Secondary ion mass spectrometry}

Secondary ion mass spectrometry (SIMS) was intensively used in this study to quantify concentrations of residual impurities as $\mathrm{C}, \mathrm{Si}, \mathrm{O}, \mathrm{H}$ and other dopants as $\mathrm{Mg}$, $\mathrm{Fe}$ in HEMT structures. It can also analyze chemical composition of alloys straightforwardly without concerning the strain effect as encountered in XRD analysis.

The SIMS analysis is done by collecting and analyzing secondary ions from the surface of the sample that is sputtered by a focused ion beam. For the focused ion beams, $\mathrm{Cs}$ or $\mathrm{O}$ ion beams are commonly used, but $\mathrm{Cs}$ is more suitable than $\mathrm{O}$ to study the III- nitride materials, partly because $\mathrm{O}$ is one of primary impurities in the materials. To determine the composition and the impurity concentration, two types of mass spectrometers were deployed. Except Fe and $\mathrm{Mg}$, most of the chemical elements in HEMT structures were analyzed by a sector field mass spectrometer, which separates the secondary ions according to their ratio of mass to charge by electrostatic and magnetic fields. For Fe and $\mathrm{Mg}$, a quadrupole mass spectrometer was used.

All the SIMS measurements of elemental depth profiles were performed by Evan Analytical Group. Depth resolutions of profiling can be customized by changing the sputtering rate. $2 \mathrm{~nm}$ - and $10 \mathrm{~nm}$ - resolutions are used for analysis of thin and thick epilayers, respectively. The detection limit for the impurities of interest in $\mathrm{GaN}$ is listed in the Table V.

Since incorporation rates of the residual impurities in GaN could largely be influenced by the growth conditions, SIMS profiling of the residual impurities in a GaN layer grown with varied growth conditions provides an efficient methodology to study the dependence between the impurity incorporations and the growth conditions.

Table V. The detection limits of various impurities in the SIMS measurement

\begin{tabular}{|c|c|c|c|c|c|c|}
\hline Impurity & H & C & Si & O & Fe & Mg \\
\hline $\begin{array}{c}\text { Detection limit } \\
\text { (atom/cm } \text { (cm }^{3}\end{array}$ & $8 \mathrm{E}+17$ & $9 \mathrm{E}+15$ & $8 \mathrm{E}+15$ & $7 \mathrm{E}+15$ & $1 \mathrm{E}+15$ & $5 \mathrm{E}+14$ \\
\hline
\end{tabular}




\section{References}

[1] S.Nakamura, T. Mukai, and M. Senoh, Applied Physics Letters 64, 1687 (1994)

[2] H. Amano, N. Sawaki, I. Akasaki, and Y. Toyoda, Applied Physics Letters 48, 353 (1986)

[3] M. Asif Khan, J. N. Kuznia, J. M. Van Hove, N. Pan, and J. Carter, Applied Physics Letters 60, $3027(1992)$

[4] M. A. Littlejohn, J. R. Hauser, and T. H. Glisson, Applied Physics Letters 26, 625 (1975)

[5] J. M. Redwing, M. A. Tischler, J. S. Flynn, S. Elhamri, M. Ahoujja, R. S. Newrock, and W. C. Mitchel, Applied Physics Letters 69, 963 (1996)

[6] R. Gaska, Q. Chen, J. Yang, A. Osinsky, M. Asif Khan, and M. S. Shur, IEEE Electron Device Letters, 18, 492 (1997)

[7] U. K. Mishra, P. Parikh, and Y.F. Wu, Proceedings of the IEEE, 90, 1022 (2002)

[8] Y.-F. Wu, D. Kapolnek, J. P. Ibbetson, P. Parikh, B. P. Keller, and U. K. Mishra, IEEE Treansctions on Electronic Devices, 48, 586 (2001)

[9] E. Mitani, M. Aojima, A. Maekawa, and S. Sano, CS Mantech Conference, p.213 (2007)

[10] Y.-F. Wu, S.M. Wood, R.P. Smith, S. Sheppard, S. T. Allen, P. Parikh and J. Milligan, Int. Electron Devices Meeting, p.1 (2006)

[11] I. P. Smorchkova,a) S. Keller, S. Heikman, C. R. Elsass, B. Heying, P. Fini, J. S. Speck, and U. K. Mishra, Applied Physics Letters 77, 3998 (2000)

[12] J. Kuzmík, IEEE Electron Device Letters, 22, 510 (2001)

[13] K.Shinohara, D. C. Regan, Y. Tang, A. L. Corrion, D. F. Brown, J. C. Wong, J. F. Robinson, H. H. Fung, A. Schmitz, T. C. Oh, S. J. Kim, P. S. Chen, R. G. Nagele, A. D. Margomenos, and M. Micovic, IEEE Treansctions on Electronic Devices, 60, 2982 (2013)

[14] S. Rennesson, F. Lecourt, N. Defrance, M. Chmielowska, S. Chenot, M. Lesecq, V. Hoel, E. Okada, Y. Cordier, and J.-C. De Jaeger, IEEE Treansctions on Electronic Devices, 60, 3105 (2013)

[15] K. Cheng, M. Leys, S. Degroote, M. Germain, and G. Borghs, Applied Physics Letters 92, 192111 (2008) 
[16] X. Q. Shen, T. Takahashi, X. Rong, G. Chen, X. Q. Wang, B. Shen, H. Matsuhata, T. Ide, and M. Shimizu, Applied Physics Letters 103, 231908 (2013)

[17] D. -W. Li, J. -S. Diao, X. -J. Zhuo, J. Zhang, X. -F. Wang, C. Liu, B. -J. Zhao, K. Li, L. Yu, Y. -W. Zhang, M. He, and S. -T. Li, Journal of Crystal Growth 407, 58 (2014)

[18] H. F. Liu, S. B. Dolmanan, L. Zhang, S. J. Chua, D. Z. Chi, M. Heuken, and S. Tripathy, Journal of Applied Physics 113, 023510 (2013)

[19] O. Ambacher and V. Cimalla, Polarization Effects in Semiconductors: From Ab Initio Theory to Device applications, Springer (2007)

[20] M. D. Losego, Interfacing Epitaxial Oxides to Gallium Nitride, North Carolina State University Ph.D. Thesis, p.48-50 (2008)

[21] I. Vurgaftman and J. R. Meyer, Journal of Applied Physics 94, 3675 (2003)

[22] B. Ozpineci, L. M. Tolbert, Comparison of Wide-Bandgap Semiconductors for Power Electronics Applications, Oak Ridge National Laboratory (2003)

[23] M. E. Levinshtein, S. L. Rumyantsev. M. S. Shur, Properties of Advanced Semiconductor Materials: GaN, AlN, InN, BN, SiC, SiGe, Wiley (2001)

[24] N. Killat, M. Montes, J. W. Pomeroy, T. Paskova, K. R. Evans, J. Leach, X. Li, Ü. Özgür, H. Morkoç, K. D. Chabak, A. Crespo, J. K. Gillespie, R. Fitch, M. Kossler, D. E. Walker, M. Trejo, G. D. Via, J. D. Blevins, and M. Kuball, IEEE Electron Device Letters, 33, 366 (2012)

[25] Nidhi, S. Dasgupta, J. Lu, J. S. Speck, and U. K. Mishra, IEEE Electron Device Letters, 33, 794 (2012)

[26] O. Ambacher, B. Foutz, J. Smart, J. R. Shealy, N. G. Weimann, K. Chu, M. Murphy, A. J. Sierakowski, W. J. Schaff, and L. F. Eastman, R. Dimitrov, A. Mitchell, and M. Stutzmann, Journal of Applied Physics 87, 334 (2000)

[27] I. P. Smorchkova, L. Chen, T. Mates, L. Shen, S. Heikman, B. Moran, S. Keller, S. P. DenBaars, J. S. Speck, and U. K. Mishra, Journal of Applied Physics 90, 5196 (2001)

[28] J. P. Ibbetson, P. T. Fini, K. D. Ness, S. P. DenBaars, J. S. Speck, and U. K. Mishra, Applied Physics Letters 77, 250 (2000)

[29] H. Hasegawa, T. Inagaki, S.Ootomo, and T. Hashizume, Journal of Vacuum Science Technology B, 21, 1844 (2003)

[30] L. Hsu and W. Walukiewicz, Journal of Applied Physics 89, 1783 (2001)

[31] R. S. Balmer, K. P. Hilton, K. J. Nash, M. J. Uren, D. J. Wallis, A. Wells, M. Missous, and T. Martin, Physica Status Solidi (c) 0, 2331 (2003) 
[32] X. Wang, G. Hu, Z. Ma, J. Ran, C. Wang, H. Xiao, J. Tang, J. Li, J.Wang, Y. Zeng, J. Li, Z. Wang, Journal of Crystal Growth 298, 835 (2007)

[33] N. Maeda, K. Tsubaki, T. Saitoh, T. Tawara, N. Kobayashi, Optical Materials 23, 211 (2003)

[34] V. M. Polyakov, V. Cimalla, V. Lebedev, K. Köhler, S. Müller, P. Waltereit, and O. Ambacher, Applied Physics Letters 97, 142112 (2010)

[35] P. B. Klein, S. C. Binari, K. Ikossi, A. E. Wickenden, D. D. Koleske, and R. L. Henry, Applied Physics Letters 79, 3527 (2001)

[36] M. J. Manfra, L. N. Pfeiffer, K. W. West, H. L. Stormer, K. W. Baldwin, J. W. P. Hsu, D. V. Lang, and R. J. Molnar, Applied Physics Letters 77, 2888 (2000)

[37] Stephen W. Kaun, Man Hoi Wong, Umesh K. Mishra, and James S. Speck, Applied Physics Letters 100, 262102 (2012)

[38] G. Bastard, Wave Mechanics Applied to Semiconductor Heterostructures, Halsted, New York (1988)

[39] H. M. Manasevit, F. M. Erdmann, W. I. Simpson. J. Electrochem. Soc. 118, 1864-8 (1971)

[40] A.C. Jones, M.L. Hitchman, Chemical Vapour Deposition: Precursors, Processes and Applications, Royal Society of Chemistry (2009)

[41] G. K. Batchelor, An Introduction to Fluid Dynamics, Cambridge Mathematical Library (2000)

[42] E. F. Schubert, Doping in III-V Semiconductors, Cambridge University Press (1993)

[43] F. Rosenberger, Fundamentals of Crystal Growth, Springer, Berlin (1979)

[44] K. F. Jensen, Handbook of Crystal Growth, Elsevier Science, Amsterdam, p.543 (1994)

[45] D. W. Shaw, Journal of Crystal Growth 31, 130 (1975)

[46] G. B. Stringfellow, Organometallic Vapor-Phase Epitaxy: Theory and Practice, Academic Press (1999)

[47] Ö. Danielsson, C. Hallin, E. Janzén, Journal of Crystal Growth 252, 289 (2003)

[48] A. Sarua, H. Ji, K. P. Hilton, D. J. Wallis, M. J. Uren, T. Martin, and M. Kuball, IEEE Transactions on Electronic Devices 54, 3152 (2007)

[49] C. Hallin, F. Owman, P. Mårtensson, A. Ellison, A. Konstantinov, O. Kordina, E. Janzén, Journal of Crystal Growth 181, 241 (1997) 
[50] J. Hassan, J. P. Bergman, A. Henry, E. Janzén, Journal of Crystal Growth 310, 4430 (2008)

[51] T. Kimoto, A.Itoh, and H. Matsunami, Applied Physics Letters 66, 3645 (1995)

[52] D. D. Koleske, A. E. Wickenden, R. L. Henry, M. E. Twigg, J. C. Culbertson, and R. J. Gorman, Applied Physics Letters 73, 2018 (1998)

[53] S. Fernández-Garrido, G. Koblmüller, E. Calleja, and J. S. Speck, Journal of Applied Physics 104, 033541 (2008)

[54] G. Koblmüller, R. M. Chu, A. Raman, U. K. Mishra, and J. S. Speck, Journal of Applied Physics 107, 043527 (2010)

[55] F. A. Ponce, B. S. Krusor, J. S. Major Jr., W. E. Plano, and D. F. Welch, Applied Physics Letters 67, 410 (1995)

[56] S. Qu, S. Li, Y. Peng, X. Zhu, X. Hu, C. Wang, X. Chen, Y. Gao, X. Xu, Journal of Alloys and Compounds 502, 417 (2010)

[57] Athikom Manoi, James W. Pomeroy, Nicole Killat, and Martin Kuball, IEEE Electron Device Letters, 31, 1395 (2010)

[58] S. Yamada, J. -I. Kato, S. Tanaka, I. Suemune, A. Avramescu, Y. Aoyagi, N. Teraguchi, and A. Suzuki, Applied Physics Letters 78, 3612 (2001)

[59] M. Imuraa, H. Sugimuraa, N. Okadaa, M Iwayaa, S. Kamiyamaa, H. Amanoa, I. Akasakia, A. Bandoh, Journal of Crystal Growth 310, 2308 (2008)

[60] H. Okumura, T. Kimoto and J. Suda, Physica Status Solidi C 7, 2094 (2010)

[61] S. W. Kaun, M. H. Wong, S. Dasgupta, S. Choi, R. Chung, U. K. Mishra, and J. S. Speck, Applied Physics Express 4, 024101 (2011)

[62] Y. Xin, S. J. Pennycook, N. D. Browning, P. D. Nellist, S. Sivananthan, F. Omnès, B. Beaumont, J. P. Faurie, and P. Gibart, Applied Physics Letters 72, 2680 (1998)

[63] R. Dwilinski, R. Doradzinski, J. Garczynski, L. P. Sierzputowski, M. Zajac, and M. Rudzinski, Journal of Crystal Growth 311, 3058 (2009)

[64] M. Rudziński, R. Kudrawiec, L. Janicki, J. Serafinczuk, R. Kucharski, M. Zajac, J. Misiewicz , R. Doradziński, R. Dwiliński, and W. Strupiński, Journal of Crystal Growth $328,5(2011)$

[65] P. B. Klein, S. C. Binari, K. Ikossi, A. E. Wickenden, D. D. Koleske and R. L. Henry, ELECTRONICS LETTERS 37, 1550 (2001) 
[66] S. C. Binari, K. Ikossi, J. A. Roussos, W. Kruppa, D. Park, H. B. Dietrich, D.D. Koleske, A.E. Wickenden, and R.L. Henry, IEEE Treansctions on Electronic Devices, 48, 465 (2001)

[67] L. Fu, H. Lu, D. Chen, R. Zhang, Y. Zheng, T. Chen, K.Wei, and X. Liu, Applied Physics Letters 98, 173508 (2011)

[68] M. J. Uren, J. Möreke, and M. Kuball, IEEE Treansctions on Electronic Devices, 59, 3327 (2012)

[69] S. Heikman, S. Keller, S. P. DenBaars, and U. K. Mishra, Applied Physics Letters 81, 439 (2002)

[70] S. Heikman, S. Keller, T. Mates, S. P. DenBaars, U. K. Mishra, Journal of Crystal Growth 242, 55 (2002)

[71] G. Parish, S. Keller, S. P. Denbaars and U. K. Mishra, Journal of Electronic Materials 29, 15 (2000)

[72] D. D. Koleske, A. E. Wickenden, R. L. Henry, and M. E. Twigg, Journal of Crystal Growth $242,55(2002)$

[73] P. Bogusławski, E. L. Briggs and J. Bernholc, Applied Physics Letters 69, 233 (1996)

[74] A. F. Wright, Journal of Applied Physics 92, 2575 (2002)

[75] C. H. Seager, A. F. Wright, J. Yu and W. Götz, Journal of Applied Physics 92, 6553 (2002)

[76] J. L. Lyons, A. Janotti, and C. G. Van de Walle, Applied Physics Letters 97, 152108 (2010)

[77] J. L. Lyons, A. Janotti, and C. G. Van de Walle, Physical Review B 89, 035204 (2014)

[78] M. Gonschorek, J. -F. Carlin, E. Feltin, M. A. Py, and N. Grandjean, Applied Physics Letters 89,062106 (2006)

[79] T. Lim, R. Aidam, L. Kirste, P. Waltereit, R. Quay, S. Müller, and O. Ambacher, Applied Physics Letters 96, 252108 (2010)

[80] A. Gadanecz, J. Bläsing, A. Dadgar, C. Hums, and A. Krost, Applied Physics Letters 90, 221906 (2007)

[81] H. Sun, Member, A.R. Alt, H.Benedickter, E. Feltin, J.-F. Carlin, M. Gonschorek, N. Grandjean, and C. R. Bolognesi, IEEE Electron Device Letters, 31, 293 (2010)

[82] Masanobu Hiroki, Narihiko Maeda, and Takashi Kobayashi, Applied Physics Express 1, $111102(2008)$ 
[83] Jinqiao Xie, Xianfeng Ni, Mo Wu, Jacob H. Leach, Ümit Özgür, and Hadis Morkoç, Applied Physics Letters 91, 132116 (2007)

[84] R. Vetury, N. Q. Zhang, S. Keller, and U. K. Mishra, IEEE Treansctions on Electronic Devices 48, 560 (2001)

[85] J. Derluyn, S. Boeykens, K. Cheng, R. Vandersmissen, J. Das, W. Ruythooren, S. Degroote, M. R. Leys, M. Germain, and G. Borghs, Applied Physics Letters 98, 054501 (2005)

[86] Z. H. Feng, Y. G. Zhou, S. J. Cai, and Kei May Lau, Applied Physics Letters 85, 5248 (2004)

[87] P. Waltereit, S. Müller, K. Bellmann, C. Buchheim, R. Goldhahn, K. Köhler, L. Kirste, M. Baeumler, M. Dammann, W. Bronner, R. Quay, and O. Ambacher, Journal of Applied Physics 106, 023535 (2009)

[88] P. Ivo, A. Glowacki, R. Pazirandeh, E. Bahat-Treidel, R. Lossy, J. Würfl, C. Boit, G. Tränkle, IEEE CFP09RPS-CDR 47th Annual International Reliability, Physics Symposium, Montreal, $71(2009)$

[89] R. Gutt, M. Himmerlich, M. Fenske, S. Müller, T. Lim, L. Kirste, P. Waltereit, K. Köhler, S. Krischok, and T. Fladung, Journal of Applied Physics 110, 083527 (2011)

[90] G. L. Miller, D. A. H. Robinson, and J. D. Wiley, Review of Scientific Instruments 47, 799 (1976)

[91] D. Nguyen_, K. Hogan, A. Blew, M. Cordes, Journal of Crystal Growth 272, 59 (2004)

[92] P F Fewster, X-Ray Scattering from Semiconductors 2nd edn, Imperial College Press, London (2003)

[93] H. Angerer, D. Brunner, F. Freudenberg, O. Ambacher, M. Stutzmann, R. Höpler, T. Metzger, E. Born, G. Dollinger, A. Bergmaier, S. Karsch, and H.-J. Körner, Applied Physics Letters 71, 1504 (1997)

[94] M. A. Moram and M. E. Vickers, Reports of Progress in Physics 72, 036502 (2009)

[95] S. K. Mathisa, A. E. Romanovb, L. F. Chena, G. E. Beltzc,W. Pomped, and J. S. Speck, Journal of Crystal Growth 231, 371 (2001)

[96] B. Heying, X. H. Wu, S. Keller, Y. Li, D. Kapolnek, B. P. Keller, S. P. DenBaars, and J. S. Speck, Applied Physics Letters 65, 643 (1995)

[97] A. Saxler, P. Debray, R. Perrin, S. Elhamri, and W. C. Mitchel, C. R. Elsass, I. P. Smorchkova, B. Heying, E. Haus, P. Fini, J. P. Ibbetson, S. Keller, P. M. Petroff, S. P. DenBaars, U. K. Mishra, and J. S. Speck, Journal of Applied Physics 87, 369 (2000) 


\section{Publications}

\section{Papers included in the thesis}

1. Low thermal resistance of a GaN-on-SiC transistor structure with improved structural properties at the interface

Jr-Tai Chen, James W. Pomeroy, Niklas Rorsman, Chao Xia, Chariya Virojanadara, Urban Forsberg, Martin Kuball, and Erik Janzén

Submitted to Journal of Crystal Growth

My contributions:

I designed, planned and performed all growth runs and characterizations, except the X-ray photoelectron spectroscopy and the Raman thermography measurements. I analyzed the data and wrote the paper.

2. Impact of residual carbon on two-dimensional electron gas properties in $\mathrm{Al}_{\mathbf{x}} \mathrm{Ga}_{1-\mathrm{x}} \mathrm{N} / \mathrm{GaN}$ heterostructure

Jr-Tai Chen, Urban Forsberg, and Erik Janzén

Applied Physics Letters 102, 193506 (2013)

My contributions:

I initiated, planned and performed all growth runs and characterizations. I analyzed the data and wrote the paper.

3. Room-Temperature mobility above $2100 \mathrm{~cm}^{2} / \mathrm{V}$-s of two-dimensional electron gas in a sharp-interface AIGaN/GaN heterostructure

Jr-Tai Chen, Ingemar Persson, Daniel Nilsson, Chih-Wei Hsu, Urban Forsberg, Per Persson and Erik Janzén

Submitted to Applied Physics Letters

My contributions:

I initiated, planned and performed growth runs and characterizations, except the transmission electron microscopy measurement and the contact fabrication and resistance measurement. I analyzed the data and wrote the paper. 


\section{Growth optimization of AlGaN/GaN HEMT structures on $100 \mathrm{~mm}$ SiC substrate: Utilizing bottom-to-top approach}

Jr-Tai Chen, Urban Forsberg, Olle Kordina, and Erik Janzén

In manuscript

My contributions:

I designed, planned and performed all growth runs and characterizations, except the transmission electron microscopy measurement and the contact fabrication and resistance measurement. I analyzed the data and wrote the paper.

5. MOCVD growth of high-mobility AIGaN/AIN/GaN heterostructures on GaN templates and native GaN substrates

Jr-Tai Chen, Urban Forsberg, Olle Kordina, and Erik Janzén

Journal of Applied Physics 117, 085301 (2015)

My contributions:

I designed, planned and performed all growth runs and characterizations. I analyzed the data and wrote the paper.

\section{Dispersive effects in AlGaN/AIN/GaN HEMTs with carbon-doped buffer}

Sebastian Gustafsson, Jr-Tai Chen, Johan Bergsten, Urban Forsberg,

Mattias Thorsell, Erik Janzén, Niklas Rorsman

Submitted to IEEE transactions on Electron Devices

My contributions:

I planned and performed growth runs and material characterizations. I analyzed the data and contributed part of paper writing.

\section{Impact of $\mathrm{AlGaN/GaN} \mathrm{interface} \mathrm{sharpness} \mathrm{on} \mathrm{HEMT} \mathrm{performance}$}

Johan Bergsten, Jr-Tai Chen, Sebastian Gustafsson, Urban Forsberg, Mattias Thorsell, Erik Janzén, and Niklas Rorsman

In manuscript

My contributions:

I planned and performed growth runs and material characterizations. I analyzed the data and contributed part of paper writing. 


\section{Papers not included in the thesis}

1. Temperature dependent effective mass in AIGaN GaN high electron mobility transistor structures

T. Hofmann, P. Kühne, S. Schöche, Jr-Tai Chen, U. Forsberg, E. Janzén, N. Ben Sedrine, C. M. Herzinger, J. A. Woollam, M. Schubert, and V. Darakchieva

Applied Physics Letters 101, 192102 (2012)

My contributions:

I performed the growth run and the routine characterizations.

\section{Presentations in conferences}

1. High-mobility InAIN-barrier HEMT structures grown by hot-wall MOCVD

Jr-Tai Chen, Anders Lundskog, Urban Forsberg, Justinas Palisaitis, Per Persson and Erik Janzén

Poser presentation, ISGN-3th, Montpellier, France (2010)

2. Growth temperature effect on two-dimensional electron gas properties in AlGaN/GaN heterostructure

Jr-Tai Chen, Ian Booker, Ivan G. Ivanov, Urban Forsberg, and Erik Janzén

Poser presentation, ISGN-4th, Saint Petersburg, Russia (2012)

3. Nearly perfect structural quality of GaN high electron mobility structure grown on native GaN substrate

Jr-Tai Chen, Chih-Wei Hsu, Urban Forsberg, and Erik Janzén

Poser presentation, ESA-7th, Frascati, Italy (2014) 


\section{Papers}

The articles associated with this thesis have been removed for copyright reasons. For more details about these see:

http://urn.kb.se/resolve?urn=urn:nbn:se:liu:diva-117138 